\title{
Cooperative binding in a phosphine oxide-based halogen bonded dimer drives supramolecular oligomerization
}

\author{
Leonardo Maugeri, Tomáš Lébl, David B. Cordes, Alexandra M. Z. Slawin and Douglas Philp* \\ EaStChem and School of Chemistry, University of St Andrews, North Haugh, St Andrews KY16 9ST, United Kingdom
}

\begin{abstract}
Triphenylphosphine oxide forms halogen-bonded (XB) complexes with pentafluoroiodobenzene and a 1,4-diaryl-5iodotriazole. The stability of these complexes is assessed computationally and by ${ }^{31} \mathrm{P}$ NMR spectroscopy in $d_{8}$-toluene solution, where both complexes are weakly associated. This knowledge is applied to the design and synthesis of two self-complementary phosphine oxide-iodotriazole hybrids that incorporate a phosphine oxide XB acceptor and a 1,4-diphenyl-5-iodotriazole XB donor within the same molecule. The self-complementary design of these modules facilitates their assembly in both $d_{8}$-toluene and, surprisingly, $d_{2}$-DCM into dimers, with significant stabilities, through the formation of halogen-bonded diads. The stability of these assemblies is a result of significant levels of cooperative binding that is present in both solvents. The connection of two of these hybrid units together, using a flexible spacer, facilitates the aggregation of these modules in $d_{2}$-DCM solution, through halogen bonding, forming oligomeric assemblies.
\end{abstract}

\section{INTRODUCTION}

Over the last two decades, the halogen bond $(\mathrm{XB})-$ the noncovalent interaction ${ }^{1}$ between an electron-deficient halogen atom and a Lewis base - has evolved from a weak intermolecular interaction of largely academic curiosity usually discussed in the context of solid state structures to a fully-fledged member of the supramolecular toolkit. Undoubtedly, this dramatic change is a result of the seminal work of the group of Metrangolo and Resnati ${ }^{2}$ and others ${ }^{3}$ during the late 1990 s and early 2000s. Today, XB interactions are employed in many fields of the chemical sciences, e.g. crystal engineering, ${ }^{4}$ medicinal chemistry, ${ }^{5}$ materials chemistry, ${ }^{6}$ nanoscience. ${ }^{7}$ Fundamental studies $^{8}$ have highlighted how single point XB complexes between well-studied classes of neutral donors and acceptors in the solid state are generally weak when transferred to solution. Therefore, the creation of functional XB-based supramolecular assemblies that are stable in solution requires complexes between XB donors and acceptors with far higher intrinsic stabilities than those involved in classical, solid state studies. Several research groups have circumvented these limitations by implementing cationic XB donors within organic structures, thus realizing a variety of molecular scaffolds able to perform as sensors ${ }^{9}$ and supramolecular catalysts ${ }^{10}$ through charge-assisted halogen bonding. An alternative strategy to overcome the limited stability of single point neutral XB interactions involves exploiting cooperativity. ${ }^{11}$ The design of trimeric, ${ }^{12}$ tetrameric, ${ }^{13}$ even polymeric ${ }^{14}$ XB donors, based on the iodoperfluorobenzene unit, able to interact with complementary multidentate $\mathrm{XB}$ acceptors has allowed the realization of multipoint XB complexes with stability constants comparable to those shown by conventional noncovalent interactions in solution.
The last 30 years has seen an explosion of non-covalent assemblies that are stabilized through the concatenation of hydrogen bond donors and acceptors into contiguous diads, ${ }^{15}$ triads ${ }^{16}$ and tetrads, ${ }^{17}$ giving rise to a rich diversity of supramolecular oligo- and polymeric assemblies that are stable in solution. However, this approach to the construction of noncovalent assemblies stabilized by halogen bonds is still in its infancy. Our laboratory has developed self-complementary diads that exploit the XB donating properties of 1,4-diphenyl5 -iodotriazoles and their interaction with both neutral nitrogen $^{18}$ and charged oxygen ${ }^{19} \mathrm{XB}$ acceptors to afford halogenbonded dimers with measurable stability in organic solvents. Systems that bear a formal charge present a particular design challenge when considering self-complementary structures, as these assemblies suffer inherently through their design from significant electrostatic repulsion. In this work, we describe an optimized self-complementary dimeric design that features an iodotriazole $\mathrm{XB}$ donor and a triphenylphosphine oxide as the $\mathrm{XB}$ acceptor. Phosphine oxides incorporate an acceptor atom that bears a formal charge within a functional group that is neutral overall. Therefore, this functional group represents an excellent compromise between weak, neutral XB acceptors, such as pyridine, and charged phenoxide XB acceptors, which introduce significant electrostatic repulsion when incorporated within homodimeric assemblies. Despite the fact that Rissanen and co-workers have highlighted ${ }^{20}$ the potential of $N$-oxides as $\mathrm{XB}$ acceptors in solution recently, there are few fundamental studies that focus on XBs formed between $N$-oxides ${ }^{21}$ or phosphine oxides ${ }^{22}$ and typical XB donors, especially in solution. Here, we report the computational and experimental assessment of the interaction between triphenylphosphine oxide and neutral XB donors. This knowledge is applied to the design and synthesis of self-complementary phosphine oxide- 
iodotriazole hybrid -incorporating both a phosphine oxide XB acceptor and a 1,4-diphenyl-5-iodotriazoles XB donor within the same molecule. This module is capable of homodimerization as a halogen bonded diad in both $d_{8}$-toluene and $d_{2}$-DCM and this assembly exhibits significant levels of cooperative binding in both solvents. The connection of two of these hybrid units together, using a flexible spacer, facilitates the aggregation of these modules in solution, through halogen bonding, forming oligomeric assemblies.

\section{RESULTS AND DISCUSSION}

The ability of phosphine oxides to accept halogen bonds has been well documented ${ }^{22 \mathrm{a}-\mathrm{d}}$ in the solid state. The highly polarized nature of the phosphorus-oxygen bond renders the oxygen atom a strong Lewis base and, thus, a powerful XB acceptor able to promote the formation ${ }^{22 a}$ of cocrystals with a variety of $\mathrm{XB}$ donors that are otherwise hard to crystallize. In solution, on the other hand, only a handful of association constants have been reported for $\mathrm{XB}$ complexes formed between phosphine oxides, acting as the $\mathrm{XB}$ acceptor and $\mathrm{XB}$ donors, such as perfluorohalocarbons ${ }^{8 \mathrm{~b}, 23}$ (PFHCs) and phenyliodoacetylenes. $^{8 \mathrm{~d}}$

In order to facilitate the design of more complex structures, we initially probed the structure and bonding in simple complexes formed between triphenylphosphine oxide TPPO and perfluoroiodobenzene PFIB and model iodotriazole ITZ. We performed a series of calculations on the [PFIB-TPPO] and [ITZ-TPPO] complexes in toluene solution at the TPSSh/def2-TZVP level of theory. The geometries and stabilities of the two complexes are shown in Figure 1a. (a)

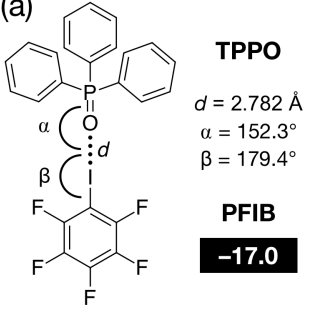

(b)
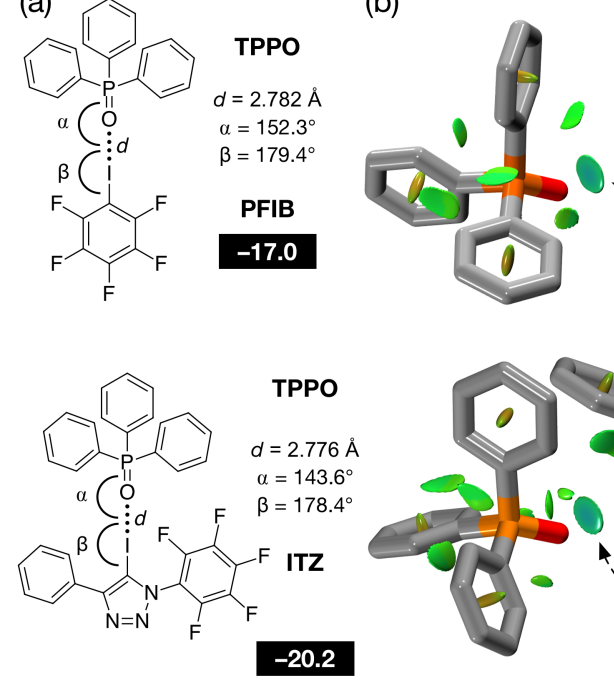
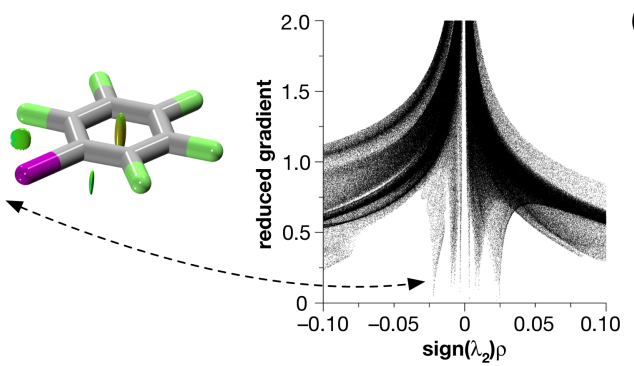

(c)

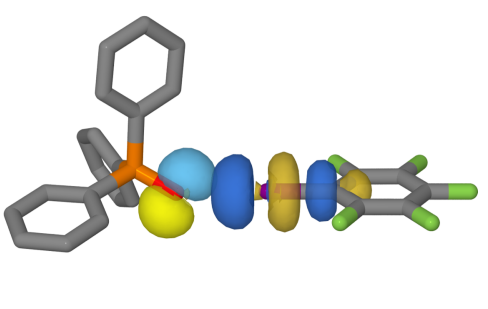

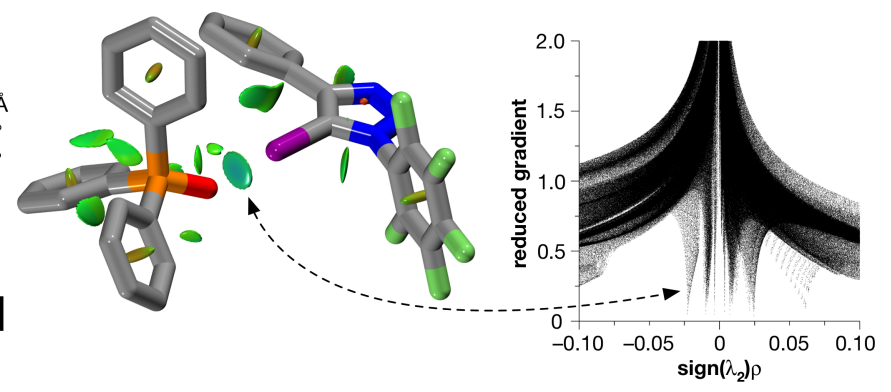

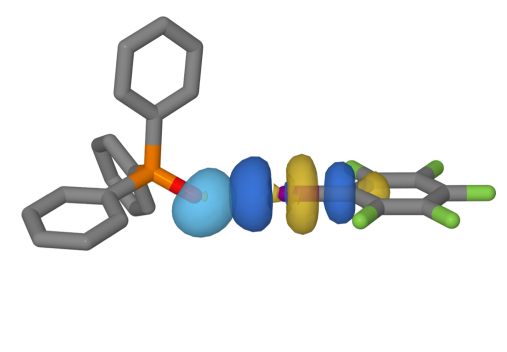

Figure 1. (a) Geometric parameters and calculated enthalpies of complexation (numbers in bold type, in $\mathrm{kJ}$ at $298 \mathrm{~K}$ ) for the complexes [PFIB-TPPO] and [ITZ·TPPO]. (b) Visualization of the non-covalent interactions present in the complexes [PFIB-TPPO] and [ITZ•TPPO]. Left: Intermolecular interaction isosurfaces generated by NCIPLOT ${ }^{24}$ for $\mathrm{s}=0.5$ and $-0.05<$ $\operatorname{sign}\left(\lambda_{2}\right) \rho<0.05$ (colour scale: attractive (blue) $\rightarrow$ repulsive (red)). Right: Plots of $\operatorname{sign}\left(\lambda_{2}\right) \rho$ vs. reduced gradient highlighting the favourable interaction corresponding to the halogen bond at $\operatorname{sign}\left(\lambda_{2}\right) \rho \sim-0.035$. Atom colouring: $\mathrm{C}$ atoms $=$ gray, $\mathrm{N}$ atoms $=$ blue, $\mathrm{O}$ atoms $=$ red, I atoms $=$ purple, $\mathrm{P}$ atoms $=$ orange. $\mathrm{H}$ atoms omitted for clarity. (c) Visualization of the $n \rightarrow \sigma^{*}$ interactions present in the [PFIB-TPPO] complex. Equivalent interactions are also present in the [ITZ•TPPO], see Supporting Information.

Both complexes have enthalpies of complexation that are

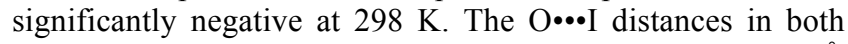
complexes are similar $-[$ PFIB•TPPO $], d(\mathrm{O} \bullet \bullet \mathrm{I})=2.782 \AA$ and $[\mathbf{I T Z} \cdot \mathbf{T P P O}], d(\mathrm{O} \bullet \bullet \mathrm{I})=2.776 \AA-$ and are significantly less than the sum of the van der Waals radii for $\mathrm{O}$ and $\mathrm{I}(\Sigma \mathrm{vdw}$ $=3.50 \AA$ ). These distances are similar to those calculated ${ }^{19}$ at the same level of theory for neutral XB acceptors, such as the oxygen atom in 4-pyridone $(d(\mathrm{O} \bullet \bullet \mathrm{I}) \sim 2.80 \AA)$, and significantly larger than those associated with anionic acceptors, such as a phenoxide oxygen atom $(d(\mathrm{O} \bullet \bullet \mathrm{I}) \sim 2.50 \AA)$. As expected, analysis of the reduced gradient ${ }^{24}$ of the electron density (Figure 1b) reveals significant low density, low gradient regions associated with the both complexes that are significantly attractive $\left(\operatorname{sign}\left(\lambda_{2}\right) \rho \sim-0.03\right)$.

We were intrigued by the geometry of these complexes in which the $\mathrm{P}-\mathrm{O}$ bond in the $\mathrm{XB}$ acceptor subtends an angle of around $150^{\circ}$ to the $\mathrm{C}-\mathrm{I}$ bond in the $\mathrm{XB}$ donor. This geometry is readily understood in terms of the significant donation from non-bonding orbitals on the $\mathrm{O}$ atom of the phosphine oxide acceptor and the $\sigma^{*}$ orbital associated with the $\mathrm{C}-\mathrm{I}$ bond. Natural bond analysis (NBO) analysis ${ }^{25}$ (Figure 1c) reveals that the observed geometry is, in part, a result of the interplay between $\mathrm{n} \rightarrow \sigma^{*}$ donation associated with $t w o$ of the lone pairs is present on the phosphine oxide and these interactions result in a deviation of the $\mathrm{P}-\mathrm{O} \cdot \bullet \mathrm{I}$ angle observed in the complexes away from $180^{\circ}$.

In order to provide an experimental baseline for our studies, we first measured the association between perfluoroiodobenzene PFIB (the XB donor) and triphenylphosphine oxide TPPO (the XB acceptor) in $d_{8}$-toluene solution at $295 \mathrm{~K}$. The strength of this interaction in solution can be measured readily using ${ }^{31} \mathrm{P}$ NMR spectroscopy as the phosphorus chemical shift is particularly sensitive ${ }^{22 \mathrm{~d}}$ to the formation of a halogen bond. Accordingly, TPPO was titrated with increasing amounts of PFIB in $d_{8}$-toluene at $295 \mathrm{~K}$ and a $121.3 \mathrm{MHz}{ }^{31} \mathrm{P}$ NMR spectrum recorded at each titration step. Upon addition of PFIB, 
the ${ }^{31} \mathrm{P}$ resonance of TPPO was shifted significantly downfield $\left(\Delta \delta\left({ }^{31} \mathrm{P}\right)>+1.40 ;[\right.$ TPPO $]=10 \mathrm{mM} ;[$ PFIB $\left.]=500 \mathrm{mM}\right)$. These data were fitted ${ }^{26}$ to a $1: 1$ binding model for the complex [PFIB-TPPO] affording (see Supporting Information for details) a stability constant for this complex of $2.7 \pm 0.3 \mathrm{M}^{-1}$ in $d_{8}$-toluene at $295 \mathrm{~K}$. Chemical shift changes that arise from non-specific interactions associated with the addition of high concentrations of PFIB were discounted by repeating the experiment, adding hexafluorobenzene instead of PFIB. In this case, the observed chemical shift change was much smaller $(-0.22 \mathrm{ppm})$ and in an upfield, rather than a downfield, direction (see Supporting Information for further details).<smiles>CC(C)(C)c1cc(-c2nnn(-c3c(F)c(F)c(F)c(F)c3F)c2I)cc(C(C)(C)C)c1</smiles><smiles>O=P(c1ccccc1)(c1ccccc1)c1ccc(-c2nnn(-c3c(F)c(F)c(F)c(F)c3F)c2I)cc1</smiles>

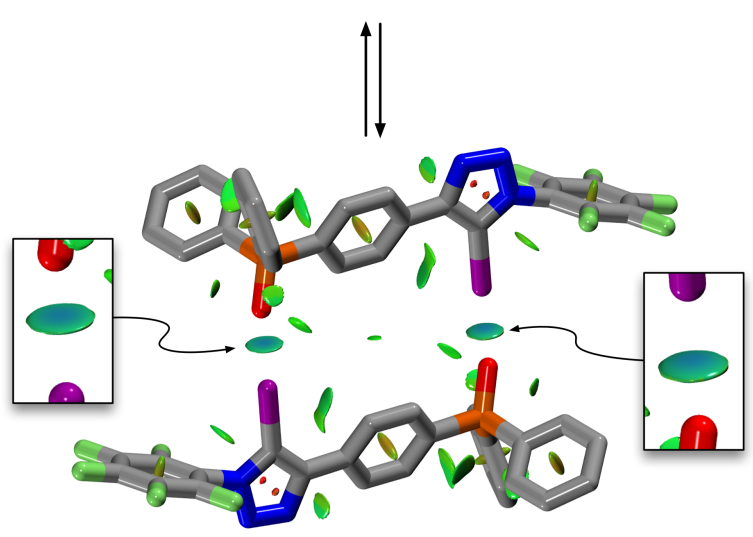

Figure 2. Connecting a triphenylphosphine oxide $\mathrm{XB}$ acceptor to an iodotriazole XB donor results in compound $\mathbf{2}$ that is capable of associating to form a homodimer stabilized by two halogen bonds. The geometry of this dimer at the TPSSh/def2-TZVP level of theory reveals an almost centrosymmetric dimer with $d(\mathrm{O} \bullet \cdot \mathrm{I})=$ $2.771 \AA$ and $d(\mathrm{O} \cdots \mathrm{I})=2.768 \AA$. Intermolecular interaction isosurfaces generated by NCIPLOT ${ }^{24}$ for $\mathrm{s}=0.5$ and $-0.05<\operatorname{sign}\left(\lambda_{2}\right) \rho$ $<0.05$ (colour scale: attractive (blue) $\rightarrow$ repulsive (red)) highlights the favourable interaction corresponding to the halogen bond at $\operatorname{sign}\left(\lambda_{2}\right) \rho \sim-0.05$ (pale blue isosurface). Atom colouring: $\mathrm{C}$ atoms $=$ gray, $\mathrm{N}$ atoms $=$ blue, $\mathrm{O}$ atoms $=$ red, $\mathrm{F}$ atoms $=$ green, $\mathrm{P}$ atoms $=$ orange, $\mathrm{I}$ atoms $=$ purple. $\mathrm{H}$ atoms are omitted for clarity.

When this titration was repeated, using 4-(3,5-di-tertbutylphenyl)-5-iodo-1-(perfluorophenyl)-1H-1,2,3-triazole $\mathbf{1}$ as the $\mathrm{XB}$ donor, a similar pattern of chemical shift changes was observed for the ${ }^{31} \mathrm{P}$ resonance of TPPO $\left(\Delta \delta\left({ }^{31} \mathrm{P}\right)>+2.00\right.$; [TPPO $=10 \mathrm{mM} ;[\mathbf{1}]=0-200 \mathrm{mM})$. In this instance, fitting of these data to a $1: 1$ binding model for the complex [1•TPPO] afforded (see Supporting Information for details) a stability constant of $6.0 \pm 0.3 \mathrm{M}^{-1}$ in $d_{8}$-toluene at $295 \mathrm{~K}$. In common with other $\mathrm{XB}$ interactions in solution, these association constants are rather small and these results suggest that
TPPO behaves in a very similar manner to other neutral XB acceptors when interacting with neutral XB donors.

Chelate cooperativity has been used successfully in several contexts $^{27}$ for creating stable, supramolecular assemblies in solution using hydrogen bonds. In terms of XB interactions, similar exploitation ${ }^{12,13,18,19}$ of cooperativity is in its infancy. With the aim of exploiting cooperative binding within a homodimeric assembly, we designed compound 2 , which bears both an XB donor (the iodotriazole) and an XB acceptor (the phosphine oxide).

The calculated structure (TPSSh/def2TZVP) of the [2•2] homodimer (Figure 2) is approximately centrosymmetric and is characterized by two short $\mathrm{I} \bullet \bullet \mathrm{O}-\mathrm{P}$ XB contacts $-d(\mathrm{O} \bullet \bullet \mathrm{I})=$ $2.771 \AA$ and $d(\mathrm{O} \bullet \bullet \cdot \mathrm{I})=2.768 \AA$ and $\angle(\mathrm{O} \bullet \bullet \cdot \mathrm{I}-\mathrm{C})=179.8^{\circ}$. The calculated enthalpy for the formation of the homodimer in toluene at $298 \mathrm{~K}$ is $-53.8 \mathrm{~kJ}$. Examination of the reduced gradient of the electron density in dimer [2-2] reveals two low density, low gradient regions between the $\mathrm{O}$ and $\mathrm{I}$ atoms associated with the halogen bonds (pale blue, Figure 2) and some additional weakly attractive, van der Waals-like areas of interactions along the spine of the dimer (green, Figure 2). Natural Bond Orbital (NBO) analysis ${ }^{25}$ of the [2-2] dimer reveals that the sum of the second order perturbation energies for the interactions between the lone pairs located on the phosphine oxide and the $\sigma^{*}$ orbitals associated with the iodotriazole two $\mathrm{C}-\mathrm{I}$ bonds are $36.4 \mathrm{~kJ}$, suggesting that this interaction could play a relatively important role in stabilizing the homodimer.

Iodotriazole 2 was synthesized readily, starting from (4ethynylphenyl)diphenylphosphine oxide 3, (Scheme 1). Iodination of alkyne $\mathbf{3}$ was achieved by treatment with $\mathrm{N}$-iodo morpholinium iodide using a modification of the procedure described $^{28}$ by Sharpless and Fokin. The copper-catalyzed cycloaddition between iodoalkyne $\mathbf{4}$ and pentafluorophenyl azide 5, in the presence of the tris((1-benzyl-1H-1,2,3-triazol4-yl)methyl)amine TBTA, afforded the target phosphine oxide 2 in $31 \%$ overall yield starting from 3 .

\section{Scheme 1.}<smiles>C#Cc1ccc(P(=O)(c2ccccc2)c2ccccc2)cc1</smiles><smiles>O=P(c1ccccc1)(c1ccccc1)c1ccc(C#CI)cc1</smiles>

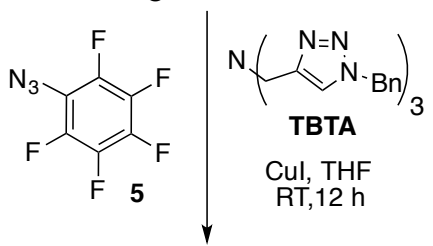<smiles>O=P(c1ccccc1)(c1ccccc1)c1ccc(-c2nnn(-c3c(F)c(F)c(F)c(F)c3F)c2I)cc1</smiles> 
In order to assess the ability of $\mathbf{2}$ to homodimerize in solution, a ${ }^{31} \mathrm{P}$ NMR dilution experiment in $d_{8}$-toluene at $295 \mathrm{~K}$ was performed. Sadly, the poor solubility of iodotriazole 2 in this solvent - a saturated solution has a concentration of less than $2 \mathrm{mM}$ - limited the range of dilution experiments that could be performed using ${ }^{31} \mathrm{P}$ NMR spectroscopy. Despite the observations of small chemical shift changes in the $202.4 \mathrm{MHz}$ ${ }^{31} \mathrm{P}$ NMR spectrum of 2 upon dilution of a $1.5 \mathrm{mM}$ solution in $d_{8}$-toluene at $295 \mathrm{~K}$ to $0.5 \mathrm{mM}$, the stability of homodimer [2-2] could not be determined from these data. We reasoned that, in order to fully exploit the homodimeric binding motif shown in Figure 2, a more soluble version of iodotriazole 2 had to be designed. This redesign focused on the replacement of the fluorine atom in the para position of the pentafluorophenyl ring in 2 with an $n$-octyl ester group. Iodotriazole 6 could be synthesized using identical methodology to that described previously (Scheme 2). Esterification of commercially available pentafluorobenzoyl chloride 7 with $n$-octanol in THF afforded ester 8. Subsequently, the $S_{N} A$ r reactivity ${ }^{29}$ of the 4position of a monosubstituted pentafluorophenyl ring was exploited to introduce the azide group into the aromatic ring by reacting 8 with sodium azide in an acetone-water mixture (1:1) affording the 1,4-disubstituted tetrafluorobenzene 9 . The final cycloaddition step between azide 9 and iodoalkyne 4 in presence of the copper(I)-TBTA complex allowed the facile preparation of the target iodotriazole $\mathbf{6}$.

\section{Scheme 2.}<smiles>O=C(Cl)c1c(F)c(F)c(F)c(F)c1F</smiles><smiles>O=C(O[Ga])c1c(F)c(F)c(F)c(F)c1F</smiles>

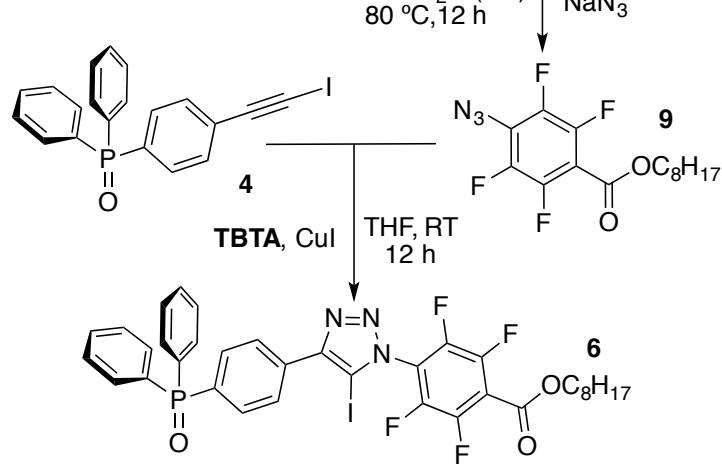

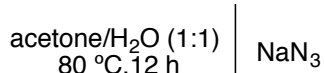
$80^{\circ} \mathrm{C}, 12 \mathrm{~h}$

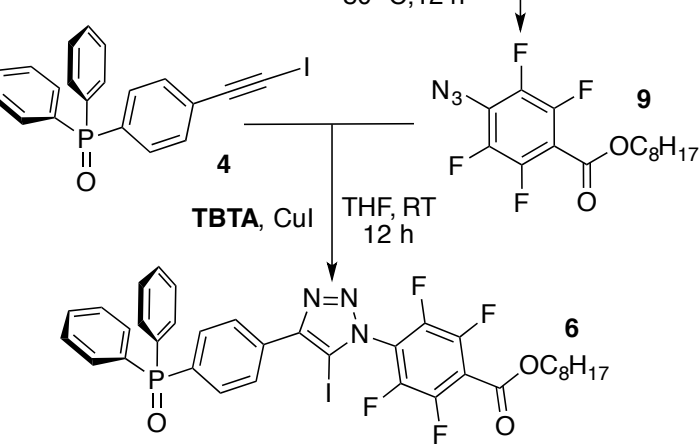

Single crystals of $\mathbf{6}$, suitable for analysis by X-ray diffraction, were grown by slow evaporation of a concentrated solution of $\mathbf{6}$ in acetonitrile. The solid-state structure of $\mathbf{6}$ reveals (Figure 3) an antiparallel orientation of the $\mathrm{P}-\mathrm{O}$ bond in $\mathbf{6}$ with respect to the $\mathrm{C}-\mathrm{I}$ bond within the same molecule and this geometry results in the formation of halogen-bonded tapes rather than discrete homodimeric assemblies. An analogous crystal packing motif is also observed for iodotriazole $\mathbf{2}$ (see Supporting Information). The halogen bonds present in the solid state structure of $\mathbf{6}$ are short $(d(\mathrm{O} \bullet \bullet \mathrm{I})=2.720 \AA, 0.8 \AA$ shorter than $\Sigma \mathrm{vdW})$ and linear $\left(\angle(\mathrm{O} \bullet \bullet \mathrm{I}-\mathrm{C})=171.5^{\circ}\right)$ and the geometry is in excellent agreement with our calculations. In addition, there are also short contacts $(0.15 \AA$ shorter than $\Sigma \mathrm{vdW}$ ) between the carbonyl oxygen atom of an ester group in one molecule of $\mathbf{6}$ and the fluorinated aromatic ring of an adjacent molecule in the crystal.

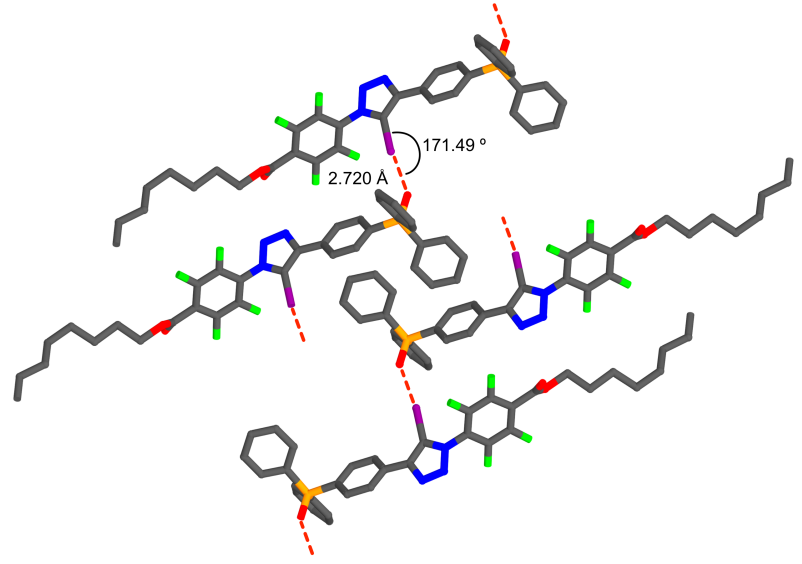

Figure 3. Stick representation of the solid-state structure of $\mathbf{6}$ determined from single crystal $\mathrm{X}$-ray diffraction data. Atom colouring: $\mathrm{C}$ atoms $=$ gray, $\mathrm{N}$ atoms $=$ blue, $\mathrm{O}$ atoms $=$ red, $\mathrm{F}$ atoms $=$ green, $\mathrm{P}$ atoms $=$ orange, $\mathrm{I}$ atoms $=$ purple

The solubility of iodotriazole $\mathbf{6}$ in toluene was found to be significantly better than that of $\mathbf{2}$ - a saturated solution of $\mathbf{6}$ in this solvent has a concentration of more than $20 \mathrm{mM}$. This improved solubility allowed us to carry out appropriate dilution experiments in $d_{8}$-toluene in order to evaluate the stability of the $\left[\mathbf{6}^{\circ} \mathbf{6}\right]$ homodimer. Significant upfield chemical shift changes for the single phosphorus resonance were observed in the $202.4 \mathrm{MHz}{ }^{31} \mathrm{P}$ NMR spectra, recorded on a solution of $\mathbf{6}$ at increasing dilutions in $d_{8}$-toluene from $20 \mathrm{mM}$ down to $1 \mathrm{mM}$. These chemical shift changes were fitted to a dimerization binding model $^{26}$ affording an association constant for the formation of the homodimeric species [6・6] $\left(K_{\text {dimer }}\right)$ of $174 \pm$ $36 \mathrm{M}^{-1}$ at $295 \mathrm{~K}$ in $d_{8}$-toluene.

In order to establish the magnitude of cooperativity achieved by connecting the phosphine oxide $\mathrm{XB}$ acceptor to the iodotriazole XB donor within the $[6 \cdot 6]$ homodimer, we quantified the effective molarity ${ }^{11}$ (EM) for binding within the $[6 \cdot 6]$ homodimer and the associated connection free energy ${ }^{30}$ $\left(\Delta \mathrm{G}^{S}\right)$. The measurement of the thermodynamic effective molarity requires determination of an appropriate reference association constant. In order to obtain this comparison data, iodotriazole 10 (Figure 4a) was prepared by copper-mediated cycloaddition of azide 9 with (iodoethynyl)benzene. Measurement of the single point association constant $K_{\text {ref }}$ for the [10-TPPO] complex at $295 \mathrm{~K}$ in $d_{8}$-toluene by ${ }^{31} \mathrm{P}$ NMR spectroscopy afforded a value of $5.6 \pm 0.5 \mathrm{M}^{-1}$ (Figures $4 \mathbf{b}$ ). The effective molarity for the formation of homodimer [6*6] can then be evaluated ${ }^{30}$ from the ratio of $K_{\text {dimer }}$ for the [6*6] homodimer to $\left(K_{\text {ref }}\right)^{2}$ - this calculation afforded a value of the $\mathrm{EM}$ of $5.7 \mathrm{M}$ and corresponds to a connection free energy, $\Delta \mathrm{G}^{S}$, of $4.3 \mathrm{~kJ} \mathrm{~mol}^{-1}$. These values are similar to the largest values reported ${ }^{27,31}$ for hydrogen-bonded dimers where EM and $\Delta \mathrm{G}^{S}$ values are available. 
(a)

(i)
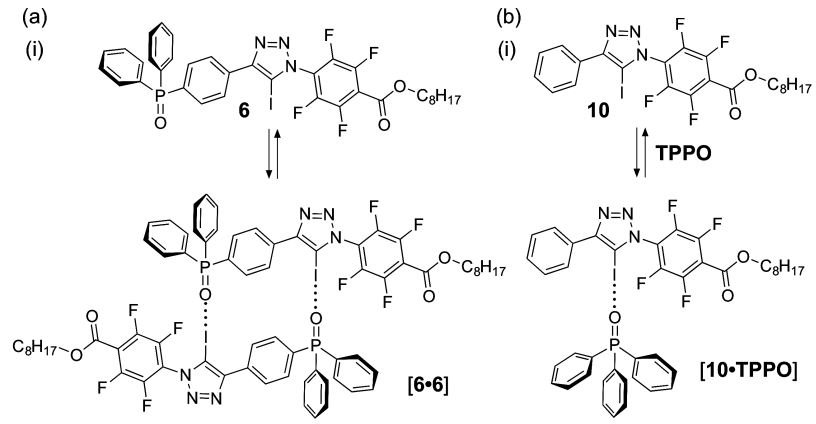

(ii)

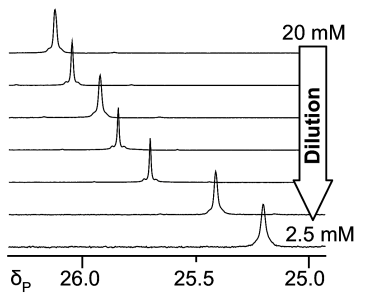

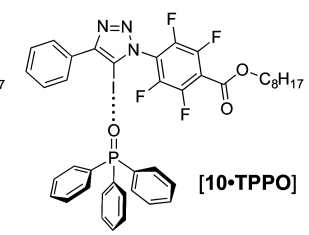

(ii)

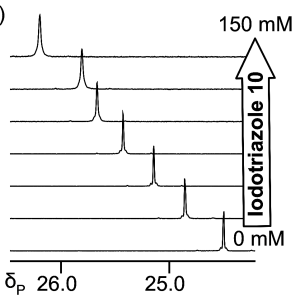

Figure 4. (a) (i) Dimerization of the phosphine oxide-appended iodotriazole 6. (ii) Partial $202.4 \mathrm{MHz}{ }^{31} \mathrm{P}$ NMR spectra showing the progressive upfield shift observed upon dilution of a $20 \mathrm{mM}$ solution of iodotriazole 6 down to $2.5 \mathrm{mM}$ in $d_{8}$-toluene at $295 \mathrm{~K}$. (b) (i) Formation of the single point $\mathrm{XB}$ complex between model iodotriazole 10 and XB acceptor TPPO. (ii) Partial 202.4 MHz ${ }^{31} \mathrm{P}$ NMR spectra showing the progressive downfield shift observed upon titrating a $10 \mathrm{mM}$ solution of TPPO with increasing amounts of iodotriazole $10(0$ to $150 \mathrm{mM})$ in $d_{8}$-toluene at $295 \mathrm{~K}$.

Given the intrinsic stability of the $[\mathbf{6} \cdot \mathbf{6}]$ homodimer and its ease of synthesis, we considered that our dimeric design could be exploited as the noncovalent binding motif of a solutionstable supramolecular polymer supported by halogen-bonded dimers. Many laboratories have demonstrated ${ }^{32}$ supramolecular polymerization driven by a variety of noncovalent interactions. All of these studies use the covalent connection of two self-complementary units using an appropriate spacer in order to achieve polymerization. However, to the best of our knowledge, this approach has never been applied to a solutionstable supramolecular polymer based on XBs. In order to exploit the $[6 \cdot 6]$ homodimer in this context, we required that two units of $\mathbf{6}$ be connected covalently. The most convenient way of realizing this objective was linking the two carboxy termini of 6 by a flexible pentamethylene spacer, affording the bis(phosphine oxide) 11. Compound $\mathbf{1 1}$ was synthesized in $32 \%$ overall yield (Scheme 3 ) using similar methodology to that employed previously.

\section{Scheme 3 .}<smiles>CC(=O)c1c(F)c(F)c(F)c(F)c1F</smiles><smiles>OCCCCCO</smiles><smiles>O=C(OCCCCOC(=O)c1c(F)c(F)c(F)c(F)c1F)c1c(F)c(F)c(F)c(F)c1F</smiles><smiles>O=P(c1ccccc1)(c1ccccc1)c1ccc(C#CI)cc1</smiles>

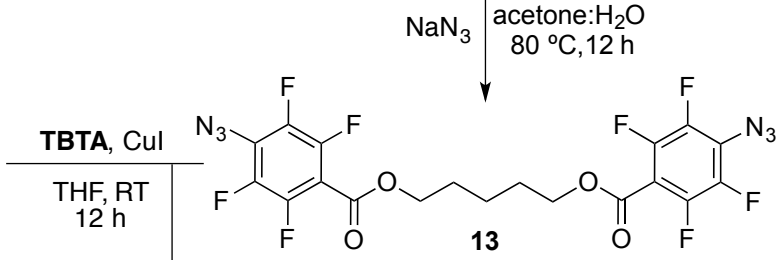

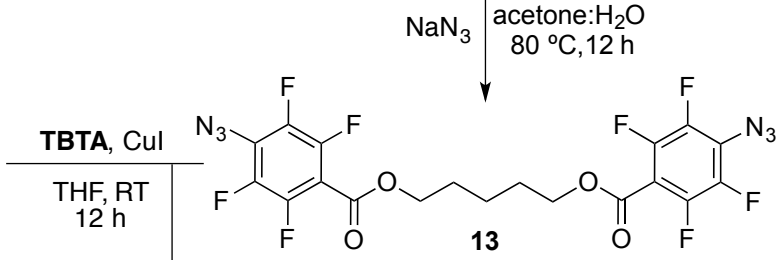<smiles>N#C/C(=C/I)c1ccc(P(=O)(c2ccccc2)c2ccccc2)cc1</smiles>

$\mathrm{NaN}_{3} \mid \begin{gathered}\text { acetone: } \mathrm{H}_{2} \mathrm{O} \\ 80^{\circ} \mathrm{C}, 12 \mathrm{~h}\end{gathered}$

$F$<smiles>CCCCOC(=O)c1c(F)c(F)c(-n2nnc(-c3ccc(P(=O)(c4ccccc4)c4ccccc4)c(F)c3I)c2I)c(F)c1F</smiles>

In common with iodotriazole 2, compound 11 displayed very poor solubility in $d_{8}$-toluene - a saturated solution of 11 in this solvent has a concentration below $2 \mathrm{mM}$. Fortuitously, however, 11 is freely soluble in $d_{2}$-DCM - solutions with concentrations of up to $500 \mathrm{mM}$ can be prepared readily at room temperature. Therefore, we performed an experiment in which a solution of 11 in $d_{2}$-DCM at $298 \mathrm{~K}$ was diluted from a starting concentration of $500 \mathrm{mM}$ to $1 \mathrm{mM}$ in eight steps and the chemical shift of the single ${ }^{31} \mathrm{P}$ resonance arising from 11 was determined by $202.4 \mathrm{MHz}{ }^{31} \mathrm{P}$ NMR spectroscopy at each step. There is a significant upfield shift of this resonance from 28.5 ppm at $500 \mathrm{mM}$ to $27.0 \mathrm{ppm}$ at $1 \mathrm{mM}$. In addition, the single ${ }^{31} \mathrm{P}$ resonance arising from $\mathbf{1 1}$ is relatively broad at high concentrations, becoming progressively sharper upon dilution.
The upfield shift, together with the concomitant sharpening of the ${ }^{31} \mathrm{P}$ resonance observed upon dilution, suggests the formation of molecular aggregates of 11, stabilized by halogen bonds, that are larger than the dimer $[\mathbf{1 1 \bullet 1 1}]$.

In order to evaluate this hypothesis, it is necessary to understand the behavior of the core intermolecular interaction driving the oligomerization of 11, namely the homodimerization of the phosphine oxide-iodotriazole hybrid modules, in $d_{2^{-}}$ DCM solution. Since $\mathbf{1 1}$ is a covalently linked dimer of $\mathbf{6}$, this process can be modelled readily by studying the assembly of homodimer [6*6] in $d_{2}$-DCM. Halogen bonds formed between neutral organic XB donors and acceptors usually have limited stabilities $^{8 \mathrm{~b}, 23}$ in halogenated solvents such as $d_{2}$-DCM. Therefore, we firstly assessed the formation of the single point $\mathrm{XB}$ 
complex [10•TPPO] in $d_{2}$-DCM. The addition of increasing amounts of iodotriazole $\mathbf{1 0}$ (from 1 to 10 equivalents) to a 5 $\mathrm{mM}$ solution of TPPO in $d_{2}$-DCM resulted in minimal changes in the chemical shift of the ${ }^{31} \mathrm{P}$ resonance of the XB acceptor (TPPO) - the maximum chemical shift change observed was only $0.13 \mathrm{ppm}$. This result indicates that the [10•TPPO] complex is only very weakly bound in $d_{2}$-DCM and it was impossible to fit this chemical shift data to a 1:1 binding model for [10•TPPO]. By contrast, the ${ }^{31} \mathrm{P}$ chemical shift changes observed upon diluting a $200 \mathrm{mM}$ solution of iodotriazole 6 down to $1 \mathrm{mM}$ in $d_{2}$-DCM could be fitted readily to a dimerization model for the formation of [6*6], affording an association constant of $3.4 \pm 0.3 \mathrm{M}^{-1}$ for this complex. This result is somewhat surprising and confirms the presence of the cooperative effect that is the result of connecting the two XB partners within one molecular module has on the overall stability of the halogen bonded complex. Although the stability of the single point [10-TPPO] complex could not be measured directly in $d_{2}$-DCM, we can estimate its stability using the association constant of homodimer $[\mathbf{6} \cdot 6]$ in $d_{2}$-DCM. Assuming that the effective molarity measured for the homodimerization of 6 in $d_{8}$-toluene is identical in $d_{2}$-DCM, the association constant of the singly halogen bonded complex [10•TPPO] in $d_{2}$-DCM is $0.8 \mathrm{M}^{-1}$, corresponding to half saturation concentration $K_{\mathrm{d}}$ of $1.25 \mathrm{M}$. This concentration is well beyond that which is accessible experimentally for these compounds. The determination of the association constant for the dimer $[\mathbf{6 \cdot 6}]$ at lower temperatures revealed that, as expected, this complex becomes more stable as the temperature is reduced - the association constant for $\left[\mathbf{6 \cdot 6}\right.$ ] increases from $3.2 \pm 0.6 \mathrm{M}^{-1}$ at $298 \mathrm{~K}$ to $8.8 \pm 0.7 \mathrm{M}^{-1}$ at $238 \mathrm{~K}$. These data allowed us to extract thermodynamic parameters for $[\mathbf{6} \cdot \mathbf{6}]$ dimer in $d_{2}$-DCM, affording values for $\Delta \mathrm{H}\left(-9.3 \mathrm{~kJ} \mathrm{~mol}^{-1}\right)$ and $\Delta \mathrm{S}\left(-2.6 \mathrm{~J} \mathrm{~mol}^{-1} \mathrm{~K}^{-1}\right)$ of binding. Therefore, the association of $\left[\mathbf{6}^{* 6}\right]$ is driven by a favorable enthalpic term, offset by a modestly unfavorable entropic contribution. These observations match ${ }^{8 \mathrm{~d}, 13 \mathrm{~b}}$ those of other halogen-bonded systems where enthalpy and entropy data are available. With this information in hand, we were now able to construct a plausible model that describes the ${ }^{31} \mathrm{P}$ NMR chemical shift changes that are observed when solutions of $\mathbf{1 1}$ in $d_{2}$-DCM are diluted. (a)

$$
\begin{gathered}
11 \stackrel{K_{1}}{\rightleftarrows}[11]_{2} \stackrel{K_{1}}{\rightleftarrows}[11]_{3} \stackrel{K_{1}}{\rightleftarrows}[11]_{4} \stackrel{K_{1}}{\rightleftarrows} \ldots[11]_{n} \\
\delta\left({ }^{31} \mathrm{P}\right)=\delta_{\text {free }}+\Delta \delta_{\text {limit }} \frac{2 K_{1}[\mathbf{1 1}]_{\text {total }}+1-\sqrt{4 K_{1}[\mathbf{1 1}]_{\text {total }}+1}}{2 K_{1}[\mathbf{1 1}]_{\text {total }}}
\end{gathered}
$$

(b)
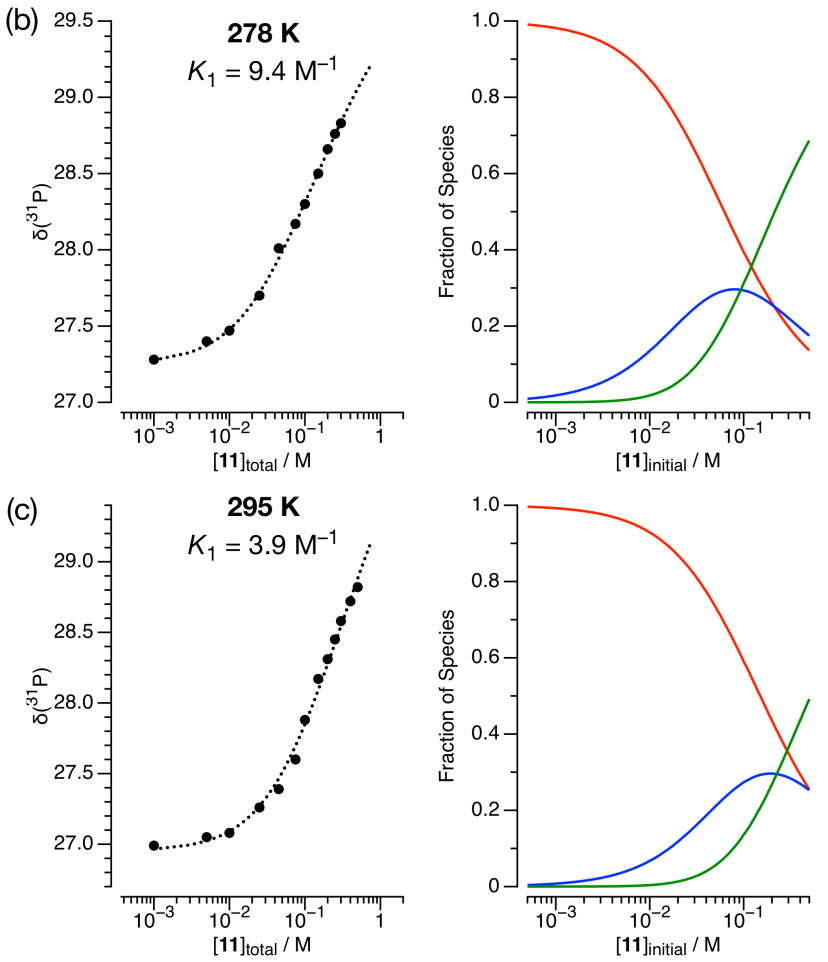

(d)

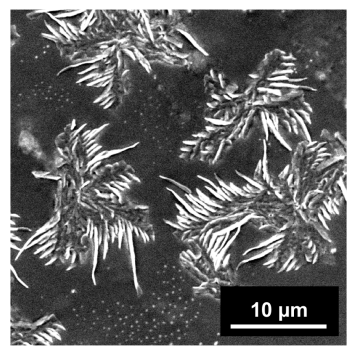

(e)

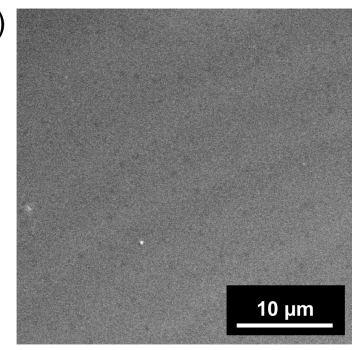

Figure 5. (a) Isodesmic or equal $K$ model of supramolecular polymerization. The expected ${ }^{31} \mathrm{P}$ chemical shift, $\delta\left({ }^{31} \mathrm{P}\right)$, can be computed from the unbound chemical shift, $\delta_{\text {free}}$, the limiting chemical shift difference between bound and unbound states, $\Delta \delta_{\text {limit }}$, the association constant, $K_{1}$, and [11 $]_{\text {total }}$. Best fits (dotted lines) of the isodesmic model to ${ }^{31} \mathrm{P}$ chemical shift data (filled circles) for solutions of $\mathbf{1 1}$ in $d_{2}$-DCM at $278 \mathrm{~K}$ (b, left) and $295 \mathrm{~K}$ (c, left). This model can also be used to predict the fraction of species in solution at $278 \mathrm{~K}$ (b, right) and $295 \mathrm{~K}$ (c, right). Red lines represent monomeric $\mathbf{1 1}$, blue lines represent the $[\mathbf{1 1}]_{2}$ dimer and green lines represent oligomers of $\mathbf{1 1}$ containing three or more monomer units. (d) Scanning electron micrograph of a sample of 6 deposited from a $20 \mathrm{mM}$ solution in $d_{2}$-DCM at $298 \mathrm{~K}$. (e) Scanning electron micrograph of a sample of $\mathbf{1 1}$ deposited from a $20 \mathrm{mM}$ solution in $d_{2}$-DCM at $298 \mathrm{~K}$.

Over the past 20 years, several models ${ }^{33}$ of non-covalent polymerization have been developed. The simplest of these models is the isodesmic or equal $K$ model $^{34}$ in which monomer units are added sequentially and reversibly to the chain ends of growing oligomers (Figure 5a) according to an equilibrium model in which each chain extension step has the same equilibrium constant, $K_{1}$. 
We could obtain excellent fits (Figures 5b and 5c, left) for the ${ }^{31} \mathrm{P}$ chemical shift data obtained for solutions of $\mathbf{1 1}$ in $d_{2^{-}}$ DCM at both $278 \mathrm{~K}$ and $295 \mathrm{~K}$ to this isodesmic oligomerization model. At $295 \mathrm{~K}$, the best fit values for the limiting chemical shift difference between the free and bound states $(+3.3 \mathrm{ppm})$ and the association constant, $K_{1},\left(3.9 \mathrm{M}^{-1}\right)$ both lie within the error limits of the values obtained for the model $[6 \cdot 6]$ dimer at a similar temperature in $d_{2}$-DCM. However, at $278 \mathrm{~K}$, although the best fit value for the limiting chemical shift difference between the free and bound states $(+2.9 \mathrm{ppm})$ is essentially identical to that determined for the $[\mathbf{6 \cdot 6}$ ] dimer at $278 \mathrm{~K}$, the best fit value of the association constant, $K_{1}$, is 9.4 $\mathrm{M}^{-1}$ is somewhat larger than that determined for the $[\mathbf{6 \cdot 6}] \mathrm{di}$ mer at $278 \mathrm{~K}\left(4.0 \mathrm{M}^{-1}\right)$. However, the two values are still within the $3 \sigma$ error limits of each other and the difference may reflect the assumptions made in deriving the isodesmic model rather than any fundamental changes in the assembly processes within the two samples. Diffusion ordered NMR spectroscopy also reveals significant differences between the aggregation behavior of the model compound 6 and 11 in $d_{2}$-DCM solution at $298 \mathrm{~K}$. Above a concentration of $50 \mathrm{mM}$, the diffusion coefficient, $D$, measured for compound $\mathbf{1 1}$ is more than three times less that that measured for compound $\mathbf{6}$ under the same conditions (see Supporting Information for details), suggesting that at higher concentrations, $\mathbf{1 1}$ is aggregated significantly. These differences in behavior can be visualized through examination of dried samples of $\mathbf{6}$ (Figure 5d) and 11 (Figure 5e) using scanning electron microscopy (SEM). These images provide further evidence for the oligomerization of $\mathbf{1 1}$ in $d_{2}$-DCM solution. Samples of $\mathbf{6}$ were deposited on the SEM target from a $20 \mathrm{mM}$ solution in $d_{2}$-DCM at room temperature and allowed to dry rapidly in air. This treatment results in the deposition of $\mu \mathrm{m}$-sized microcrystallites of $\mathbf{6}$ on the surface of the target (Figure 5d). By contrast, when the same experiment was repeated using a $20 \mathrm{mM}$ solution of 11 in $d_{2}$-DCM at room temperature, a smooth film (Figure 5e) was deposited on the surface. This film is extremely smooth over areas larger than $1500 \mu \mathrm{m}^{2}$.

\section{CONCLUSION}

In the expanding lexicon of intermolecular interactions, halogen bonds constitute a particular challenge for chemists who wish to exploit these interactions for the realization of stable and functional self-assembled structures in solution. In contrast to hydrogen bonds, there are few, if any, empirical rule sets that exist to guide the design of stable arrays of halogen bonds in solution. The results presented here highlight the potential of concatenating halogen bonds into a stable diad, which follow design rules applied to the more common hydrogen bonds. This diad exhibits considerable positive cooperativity in its assembly and facilitates the assembly of a halogenbonded dimer, constructed from neutral XB donors and acceptors, that is stable in both $d_{8}$-toluene and $d_{2}$-DCM solution. The challenge moving forward is to extend these principals to $\mathrm{XB}$ triads and tetrads that are capable of exploiting cooperative binding to create assemblies in solution that rival those created using hydrogen bonds.

\section{EXPERIMENTAL SECTION}

General Experimental Methods. All starting material were purchased from commercially available sources and used as obtained unless otherwise specified. 4-(3,5-Di-tert-butylphenyl)-5-iodo-1-
(perfluorophenyl)-1H-1,2,3-triazole ${ }^{18}$ (1), (4-ethynyl)diphenyl phosphine oxide ${ }^{35}(\mathbf{3}), N$-iodo morpholinium iodide, ${ }^{28}$ (tris $((1-$ benzyl- $1 \mathrm{H}-$ 1,2,3-triazole-4-yl)methyl) amine ${ }^{36}$ (TBTA), pentafluorophenyl az$\operatorname{ide}^{37}(\mathbf{5})$ and (iodoethynyl)benzene ${ }^{28}(\mathbf{1 2})$ were prepared according to literature procedures.

${ }^{1} \mathrm{H},{ }^{13} \mathrm{C},{ }^{19} \mathrm{~F}$ and ${ }^{31} \mathrm{P}$ NMR spectroscopic data were acquired at a constant temperature of $25{ }^{\circ} \mathrm{C}$ unless stated otherwise. ${ }^{1} \mathrm{H}$ and ${ }^{13} \mathrm{C}$ chemical shift are reported in parts per million ( $\mathrm{ppm}$ ) from high to low field and referenced to the literature values for chemical shift of the residual non-deuterated solvent, with respect to tetramethylsilane. ${ }^{19} \mathrm{~F}$ NMR chemical shift are referenced to $\mathrm{CFCl}_{3}(0.00 \mathrm{ppm}) .{ }^{31} \mathrm{P}$ chemical shift are referenced to $\mathrm{PPh}_{3}(-6.00 \mathrm{ppm})$.

Electrospray ionization (ESI) spectra were recorded in positive ion mode, $m / z$ values are reported in Daltons.

SEM samples were air-dried and coated with gold (Quorum Q150R ES) at $10 \mathrm{~mA}$ for 30 seconds, SEM images were taken with a field emission gun electron source running at $5 \mathrm{kV}$.

Association constants were determined from ${ }^{31} \mathrm{P}$ NMR spectroscopic data using WinEQNMR. ${ }^{26}$

\section{Computational Details.}

All calculations were performed using Gaussian $09^{38}$ suite of programs - revision D.01 was used in all calculations. Calculation were performed using TPSSh${ }^{39}$ functional and the def2-TZVP basis set ${ }^{40}$ of Weigend and Ahlrichs. This basis set was introduced into the calculation using the GenECP keyword and an appropriately-formatted input block for the basis set generated from data obtained from the Basis Set Exchange $^{41}$ (https://bse.pnl.gov/bse/portal). An effective core potential on iodine, ${ }^{42}$ which replaces 28 valence electrons on each iodine atom was used in all calculations. The calculations were all-electron for all other elements. All geometries were optimized fully in internal (keyword: opt) or cartesian (keyword: opt=cartesian) coordinates using the default optimisation protocols within Gaussian09. Stationary points were characterised by means of a vibrational analysis (keyword: freq) and zero-point energy corrections and other thermodynamic parameters, used in the calculation of interactions energies, were derived ${ }^{43}$ from this analysis. Population analyses using the Natural Bond Orbital (NBO) method were performed using the NBO6 program ${ }^{25}$ in a two-stage procedure. The input for NBO6 was generated using Gaussian09 (keyword: population=nboread) and the .47 file generated by this calculation was then edited and processed using the gennbo script provided with the NBO6 distribution. All analyses used the 8-byte integer version of NBO6 (6.0.13, dated July 2016) compiled from source using gfortran (Version 4.4.7). The basis set superposition error was calculated using the counterpoise method ${ }^{44}$ as implemented within Gaussian09 (keyword: counterpoise $=2$ ). Halogen bonds were visualized using the NCIPLOT $^{24}$ program. SCF densities written as an extended wavefunction file from Gaussian09 and NCIPLOT used to generate cube files from which isosurfaces could be visualised using $\mathrm{VMD}^{45}$ with $s=0.5$ and an appropriate colour map (blue (attractive) to red (repulsive)) mapped on to $-0.05<\rho<0.05$.

Synthetic Procedures. (4-(Iodoethynyl)phenyl)diphenylphosphine oxide (4). $N$-Iodomorpholinium iodide $(4.97 \mathrm{~g}, 14.6 \mathrm{mmol})$ was added to a solution of (4-ethynylphenyl)diphenylphosphine oxide $\mathbf{3}$ (3.3 g, $10.9 \mathrm{mmol}$ ) in $24.0 \mathrm{~mL}$ of THF. The mixture thus obtained was stirred at room temperature for 12 hours. After this time, the reaction was concentrated under reduced pressure to remove the bulk of the THF and redissolved in ethyl acetate and, as such, transferred into a separating funnel. The organic phase was washed three times with $1 \mathrm{M}$ sodium thiosulfate aqueous solution then brine, dried over $\mathrm{MgSO}_{4}$, filtered and concentrated in vacuo. Crystallization of the crude material in hot acetonitrile afforded $3.3 \mathrm{~g}$ of iodoalkyne 4 as a yellow solid (7.7 mmol, 53\%). Crystals suitable for single crystal X-ray diffraction were obtained upon cooling of a saturated acetonitrile solution. ${ }^{1} \mathrm{H}$ NMR $\left(500.1 \mathrm{MHz}, \mathrm{CDCl}_{3}\right): \delta 7.65-7.58(\mathrm{~m}, 6 \mathrm{H}), 7.56-7.52(\mathrm{~m}$, 
2H), $7.50-7.43(\mathrm{~m}, 6 \mathrm{H}) .{ }^{31} \mathrm{P}$ NMR $\left(202.4 \mathrm{MHz}, \mathrm{CDCl}_{3}\right): \delta 28.7 .{ }^{13} \mathrm{C}$ NMR (125.7 MHz, $\left.\mathrm{CDCl}_{3}\right)$ : $\delta 132.9(\mathrm{~d}, J=103.4 \mathrm{~Hz}, 1 \mathrm{C}), 132.3(\mathrm{~d}$, $J=12.9 \mathrm{~Hz}, 1 \mathrm{C}), 132.2(\mathrm{~d}, J=3.0 \mathrm{~Hz}, 1 \mathrm{C}), 132.1(\mathrm{~d}, J=9.9 \mathrm{~Hz}, 1 \mathrm{C})$, 132.07 (d, $J=104.3 \mathrm{~Hz}, 1 \mathrm{C}), 131.9$ (d, $J=10 \mathrm{~Hz}, 1 \mathrm{C}), 128.7$ (d, $J=10$ $\mathrm{Hz}, 1 \mathrm{C}), 127.1$ (d, $J=2.9 \mathrm{~Hz}, 1 \mathrm{C}), 93.21-93.20$ (m, 1C), 11.37 $11.32(\mathrm{~m}, 1 \mathrm{C})$. HRMS (ESI-TOF) $\mathrm{m} / \mathrm{z}:[\mathrm{M}+\mathrm{Na}]^{+}$calcd. for $\mathrm{C}_{20} \mathrm{H}_{14} \mathrm{IONaP}, 450.9701$; found 450.9719 . M.p. $>191.1^{\circ} \mathrm{C}$ dec..

(4-(5-iodo-1-(perfluorophenyl)-1H-1,2,3-triazol-4-

yl)phenyl)diphenyl phosphine oxide (2). Ligand TBTA (37 mg, 0.07 mmol) was stirred in THF $(3.0 \mathrm{~mL})$ with copper iodide $(13 \mathrm{mg}, 0.07$ $\mathrm{mmol})$ for 20 minutes. Iodoalkyne $4(0.30 \mathrm{~g}, 0.70 \mathrm{mmol})$ and azide 5 $(0.15 \mathrm{~g}, 0.70 \mathrm{mmol})$ were then dissolved in THF $(1.0 \mathrm{~mL})$ and added in a single portion to the catalyst mixture. The reaction mixture was stirred at room temperature for 12 hours and, after this time, quenched by adding an aqueous ammonium hydroxide solution $(10 \%, 0.7 \mathrm{~mL})$ and concentrated under reduced pressure. The crude mixture was then redissolved in ethyl acetate, washed with water, brine and finally dried over $\mathrm{MgSO}_{4}$, filtered and concentrated in vacuo. Purification by column chromatography ( $\mathrm{SiO}_{2}, 4: 1 \mathrm{DCM}$ : ethyl acetate), followed by crystallization from hot DCM, afforded the product as a white powder $(0.26 \mathrm{~g}, 0.41 \mathrm{mmol}, 58 \%)$. Crystals suitable for single crystal X-ray diffraction were obtained upon cooling of a saturated acetonitrile solution. ${ }^{1} \mathrm{H}$ NMR $\left(500.1 \mathrm{MHz}, \mathrm{CDCl}_{3}\right): \delta 8.19-8.17(\mathrm{~m}, 2 \mathrm{H}), 7.84-$ $7.80(\mathrm{~m}, 2 \mathrm{H}), 7.72-7.68(\mathrm{~m}, 4 \mathrm{H}), 7.59-7.56(\mathrm{~m}, 2 \mathrm{H}), 7.51-7.48(\mathrm{~m}$, 4H). ${ }^{31} \mathrm{P}$ NMR $\left(202.4 \mathrm{MHz}, \mathrm{CDCl}_{3}\right): \delta 28.9 .{ }^{19} \mathrm{~F}$ NMR $(470.5 \mathrm{MHz}$, $\left.\mathrm{CDCl}_{3}\right): \delta-142.19--142.23(\mathrm{~m}, 2 \mathrm{~F}),-146.88--146.97(\mathrm{~m}, 1 \mathrm{~F})$, $-158.86--158.99(\mathrm{~m}, 2 \mathrm{~F}) .{ }^{13} \mathrm{C}$ NMR $\left(125.7 \mathrm{MHz}, \mathrm{CDCl}_{3}\right): \delta 149.4$, $144.9-142.6(\mathrm{~m}, 1 \mathrm{C}), 139.3-136.9(\mathrm{~m}, 1 \mathrm{C}), 133.9-133.1(\mathrm{~m}, 1 \mathrm{C})$, $132.8-131.8(\mathrm{~m}, 5 \mathrm{C}), 128.7$ (d, $J=12.3 \mathrm{~Hz}, 1 \mathrm{C}), 127.3(\mathrm{~d}, J=12.1$ $\mathrm{Hz}, 1 \mathrm{C}), 112.5$ - 112.2 (m, 1C), 81.6 - 81.5 (m, 1C), 53.6. HRMS (ESI-TOF) $\mathrm{m} / \mathrm{z}$ : $[\mathrm{M}+\mathrm{Na}]^{+}$calcd. for $\mathrm{C}_{26} \mathrm{H}_{14} \mathrm{~F}_{5} \mathrm{IN}_{3} \mathrm{NaOP}$, 659.9737; found 659.9732. M.p. $>204.6^{\circ} \mathrm{C}$ dec..

Octyl 2,3,4,5,6-pentafluorobenzoate (8). Pentafluorobenzoyl chloride $7(2.00 \mathrm{~g}, 8.68 \mathrm{mmol})$ was added to a solution of $n$-octanol $(1.56$ $\mathrm{g}, 11.98 \mathrm{mmol}$ ) in $1.5 \mathrm{~mL}$ of THF and the mixture thus obtained was refluxed for 5 hours. After cooling to room temperature, the reaction mixture was treated with an aqueous saturate solution of $\mathrm{NaHCO}_{3}$, diluted with ether and, as such, transferred in a separating funnel. The organic layer was washed with brine, dried over $\mathrm{MgSO}_{4}$, filtered and concentrated under reduced pressure. Purification of the product was achieved by column chromatography of the concentrated crude $\left(\mathrm{SiO}_{2}\right.$, 4:1 petroleum ether: ethyl acetate) to afford $2.80 \mathrm{~g}$ of ester $\mathbf{8}(8.63$ mmol, $99 \%)$ as a colourless oil. ${ }^{1} \mathrm{H}$ NMR $\left(500.1 \mathrm{MHz}, \mathrm{CDCl}_{3}\right): \delta 4.36$ $(\mathrm{d}, J=6.6 \mathrm{~Hz}, 2 \mathrm{H}), 1.77-1.71(\mathrm{~m}, 2 \mathrm{H}), 1.43-1.38(\mathrm{~m}, 2 \mathrm{H}), 1.34-$ $1.26(\mathrm{~m}, 8 \mathrm{H}), 0.85(\mathrm{t}, J=6.7 \mathrm{~Hz}, 3 \mathrm{H}) .{ }^{19} \mathrm{~F}$ NMR $\left(470.5 \mathrm{MHz}, \mathrm{CDCl}_{3}\right)$ : $\delta-138.83--138.90(\mathrm{~m}, 2 \mathrm{~F}),-149.67--149.78(\mathrm{~m}, 1 \mathrm{~F}),-161.05-$ $-161.16(\mathrm{~m}, 2 \mathrm{~F}) .{ }^{13} \mathrm{C} \mathrm{NMR}\left(125.7 \mathrm{MHz}, \mathrm{CDCl}_{3}\right): \delta 159.2,146.6-$ 144.3 (m, 1C), $144.2-142.0$ (m, 1C), $138.9-136.7$ (m, 1C), 108.7 $(\operatorname{td}, J=16.2 \mathrm{~Hz}$ and $J=4.0 \mathrm{~Hz}), 67.1,31.9,29.30,29.26,28.6,25.9$, 22.8, 14.1. HRMS (ESI-TOF) $m / z$ : $[\mathrm{M}+\mathrm{Na}]^{+}$calcd. for $\mathrm{C}_{15} \mathrm{H}_{17} \mathrm{~F}_{5} \mathrm{NaO}_{2}$, 347.1046; found 347.1022.

Octyl 4-azido-2,3,5,6-tetrafluorobenzoate (9). Ester 8 (2.00 g, 6.17 $\mathrm{mmol})$ and sodium azide $(0.84 \mathrm{~g}, 12.9 \mathrm{mmol})$ were dissolved in 14.0 $\mathrm{mL}$ of a 1:1 acetone:water solution and the mixture thus obtained was heated to $80{ }^{\circ} \mathrm{C}$ for 24 hours. After this time, the reaction was quenched with water and diluted with diethylether and, as such, transferred in a separating funnel. The organic layer was quenched with brine, dried over $\mathrm{MgSO}_{4}$, filtered and concentrated in vacuo. Purification of the product was obtained by column chromatography $\left(\mathrm{SiO}_{2}\right.$, $8: 1$ to $7: 3$ petroleum ether: DCM) to afford $0.77 \mathrm{mg}$ of 9 as a yellow oil (2.22 mmol, 36\%). ${ }^{1} \mathrm{H}$ NMR (500.1 MHz, $\left.\mathrm{CDCl}_{3}\right): \delta 4.36(\mathrm{~d}, J=$ $6.6 \mathrm{~Hz}, 2 \mathrm{H}), 1.77-1.71(\mathrm{~m}, 2 \mathrm{H}), 1.44-1.38(\mathrm{~m}, 2 \mathrm{H}), 1.34-1.27(\mathrm{~m}$, $8 \mathrm{H}), 0.88(\mathrm{t}, J=7.0 \mathrm{~Hz}, 3 \mathrm{H}) .{ }^{19} \mathrm{~F}$ NMR $\left(470.5 \mathrm{MHz}, \mathrm{CDCl}_{3}\right): \delta$ $-138.87--138.97(\mathrm{~m}, 2 \mathrm{~F}),-150.99--151.09(\mathrm{~m}, 2 \mathrm{~F}) .{ }^{13} \mathrm{C}$ NMR $\left(125.7 \mathrm{MHz}, \mathrm{CDCl}_{3}\right): \delta 159.6-159.5(\mathrm{~m}, 1 \mathrm{C}), 146.5-144.2(\mathrm{~m}, 1 \mathrm{C})$, $141.7-139.5(\mathrm{~m}, 1 \mathrm{C}), 123.3-123.1(\mathrm{~m}, 1 \mathrm{C}), 108.2(\mathrm{t}, J=15.8 \mathrm{~Hz}$, 1C), 67.0, 31.9, 29.3, 29.2, 28.6, 25.9, 22.8, 14.2. HRMS (ESI-TOF) $m / z:[\mathrm{M}+\mathrm{Na}]^{+}$calcd. for $\mathrm{C}_{15} \mathrm{H}_{17} \mathrm{~F}_{4} \mathrm{~N}_{3} \mathrm{NaO}_{2}, 370.1155$; found 370.1135 .

Octyl 4-(4-(4-(diphenylphosphoryl)phenyl)-5-iodo-1H-1,2,3triazol-1-yl)-2,3,5,6-tetrafluorobenzoate (6). Ligand TBTA (64 mg, $0.12 \mathrm{mmol})$ was stirred in dry THF $(5.0 \mathrm{~mL})$ with copper iodide $(23$ $\mathrm{mg}, 0.12 \mathrm{mmol})$ for 20 minutes. Iodoalkyne $4(0.52 \mathrm{~g}, 1.21 \mathrm{mmol})$ and azide $9(0.42 \mathrm{~g}, 1.21 \mathrm{mmol})$ were dissolved in THF $(1.0 \mathrm{~mL})$ and added in a single portion to the catalyst mixture. After stirring at room temperature for 12 hours, the reaction mixture was quenched with an aqueous ammonium hydroxide solution $(10 \%, 1.2 \mathrm{~mL})$ and concentrated under reduced pressure. The crude mixture was then redissolved in ethyl acetate, washed with water and brine and successively dried over $\mathrm{MgSO}_{4}$ filtered and concentrated in vacuo. Purification was achieved by crystallization from hot acetonitrile, affording iodotriazole 6 as a white powder $(0.60 \mathrm{~g}, 0.77 \mathrm{mmol}, 64 \%)$. Crystals suitable for single crystal X-ray diffraction were obtained upon cooling of a saturated acetonitrile. ${ }^{1} \mathrm{H}$ NMR $\left(500.1 \mathrm{MHz}, \mathrm{CDCl}_{3}\right): \delta 8.20-8.17(\mathrm{~m}$, $2 \mathrm{H}), 7.84-7.80(\mathrm{~m}, 2 \mathrm{H}), 7.72-7.68(\mathrm{~m}, 2 \mathrm{H}), 7.59-7.56(\mathrm{~m}, 2 \mathrm{H})$ $7.51-7.48(\mathrm{~m}, 4 \mathrm{H}), 4.46(\mathrm{t}, J=6.6 \mathrm{~Hz}, 2 \mathrm{H}), 1.82-1.77(\mathrm{~m}, 2 \mathrm{H}), 1.47$ $-1.42(\mathrm{~m}, 2 \mathrm{H}), 1.37-1.26(\mathrm{~m}, 8 \mathrm{H}), 0.89(\mathrm{~s}, 3 \mathrm{H}) .{ }^{19} \mathrm{~F}$ NMR $(470.5$ $\left.\mathrm{MHz}, \mathrm{CDCl}_{3}\right): \delta-141.47--141.59(\mathrm{~m}, 2 \mathrm{~F}),-136.88--137.01(\mathrm{~m}$, $2 \mathrm{~F}) .{ }^{31} \mathrm{P}$ NMR $\left(202.4 \mathrm{MHz}, \quad 20 \mathrm{mM}, \quad \mathrm{CDCl}_{3}\right): \quad \delta \quad 28.91$. ${ }^{13} \mathrm{C}$ NMR $\left(125.7 \mathrm{MHz}, \mathrm{CDCl}_{3}\right): \delta 158.6,149.4,145.7-143.4(\mathrm{~m}, 1 \mathrm{C})$, $144.0-141.8(\mathrm{~m}, 1 \mathrm{C}), 133.4(\mathrm{~d}, J=103.4 \mathrm{~Hz}, 1 \mathrm{C}), 132.6-131.7(\mathrm{~m}$, 5C), $128.6(\mathrm{~d}, J=12.0 \mathrm{~Hz}, 1 \mathrm{C}), 127.2(\mathrm{~d}, J=12.5 \mathrm{~Hz}, 1 \mathrm{C}), 118.4-$ 118.1 (m, 1C), $116.3(\mathrm{t}, J=16.8 \mathrm{~Hz}, 1 \mathrm{C}), 80.8,67.7,31.8,29.14$, 29.10, 28.4, 25.7, 22.6, 14.1. HRMS (ESI-TOF) $\mathrm{m} / \mathrm{z}$ : $[\mathrm{M}+\mathrm{Na}]^{+}$calcd. for $\mathrm{C}_{35} \mathrm{H}_{31} \mathrm{~F}_{4} \mathrm{~N}_{3} \mathrm{NaIPO}_{3}$, 798.0976; found 798.0959. M.p: $>185.0{ }^{\circ} \mathrm{C}$ dec..

Octyl 2,3,5,6-tetrafluoro-4-(5-iodo-4-phenyl-1H-1,2,3-triazol-1yl)benzoate (10). Ligand TBTA (46 mg, $0.09 \mathrm{mmol}$ ) was stirred in THF (3.5 mL) with copper iodide ( $16 \mathrm{mg}, 0.09 \mathrm{mmol})$ for 20 minutes. Iodoalkyne $4(0.19 \mathrm{~g}, 0.86 \mathrm{mmol})$ and azide $9(0.30 \mathrm{~g}, 0.86 \mathrm{mmol})$ were then dissolved in THF $(0.5 \mathrm{~mL})$ and added in a single portion to the catalyst mixture. After stirring at room temperature for 12 hours, the reaction mixture was quenched with an aqueous ammonium hydroxide solution $(10 \%, 0.8 \mathrm{~mL})$ and concentrated under reduced pressure. The crude mixture was then redissolved in ethyl acetate washed with water and brine and successively dried over $\mathrm{MgSO}_{4}$ filtered and concentrated in vacuo. Purification was achieved by crystallization from hot acetonitrile, affording iodotriazole $\mathbf{1 0}$ as a white powder (0.60 g, $0.77 \mathrm{mmol}, 64 \%) .{ }^{1} \mathrm{H}$ NMR $\left(500.1 \mathrm{MHz}, \mathrm{CDCl}_{3}\right): \delta 8.05-$ $8.03(\mathrm{~m}, 2 \mathrm{H}), 7.54-7.45(\mathrm{~m}, 3 \mathrm{H}), 4.46(\mathrm{t}, J=6.5 \mathrm{~Hz}, 2 \mathrm{H}), 1.83-1.77$ $(\mathrm{m}, 2 \mathrm{H}), 1.48-1.42(\mathrm{~m}, 2 \mathrm{H}), 1.37-1.22(\mathrm{~m}, 8 \mathrm{H}), 0.89(\mathrm{t}, J=6.4 \mathrm{~Hz}$, $3 \mathrm{H}) .{ }^{19} \mathrm{~F}$ NMR $\left(470.5 \mathrm{MHz}, \mathrm{CDCl}_{3}\right): \delta-137.11--137.18(\mathrm{~m}, 2 \mathrm{~F})$, $-141.51--141.58(\mathrm{~m}, 2 \mathrm{~F}) .{ }^{13} \mathrm{C}$ NMR $\left(125.7 \mathrm{MHz}, \mathrm{CDCl}_{3}\right): \delta 158.6$, 150.6, 145.7 - 143.4 (m, 1C), 144.1 - 141.9 (m, 1C), 129.3, 129.0, $128.8,127.5,118.6-118.3(\mathrm{~m}, 1 \mathrm{C}), 116.1(\mathrm{t}, J=16.8 \mathrm{~Hz}, 1 \mathrm{C}), 79.4$, 67.6, 31.8, 29.14, 29.10, 28.4, 25.7, 22.6, 14.1. HRMS (ESI-TOF) $m / z:[\mathrm{M}+\mathrm{H}]^{+}$calcd. for $\mathrm{C}_{23} \mathrm{H}_{23} \mathrm{~F}_{4} \mathrm{IN}_{3} \mathrm{O}_{2}$, 576.0766; found 576.0752. M.p. $109.3-111.3^{\circ} \mathrm{C}$.

Pentane-1,5-diyl bis(2,3,4,5,6-pentafluorobenzoate $)^{46}$ (12). Pentafluorobenzoyl chloride $7(8.8 \mathrm{~g}, 38.2 \mathrm{mmol})$ was added to a solution of 1,5-pentane diol $(2.0 \mathrm{~g}, 19.2 \mathrm{mmol})$ in $6.4 \mathrm{~mL}$ of THF and the mixture thus obtained was refluxed for 12 hours. After cooling the reaction mixture to room temperature, a saturate solution of $\mathrm{NaHCO}_{3}$ was added to neutralize the acid, the mixture was diluted with ethyl ether and, as such, transferred in a separating funnel. The organic layer was then washed with brine, dried over $\mathrm{MgSO}_{4}$, filtered and concentrated under reduced pressure to obtain $4.8 \mathrm{~g}$ of bis-ester $\mathbf{1 2}$ (9.8 mmol, $51 \%)$ as a colorless oil. ${ }^{1} \mathrm{H} \mathrm{NMR}\left(500.1 \mathrm{MHz}, \mathrm{CDCl}_{3}\right): \delta$ $4.40(\mathrm{t}, J=7.1 \mathrm{~Hz}, 2 \mathrm{H}), 1.85-1.80(\mathrm{~m}, 2 \mathrm{H}), 1.62-1.55(\mathrm{~m}, 1 \mathrm{H}) .{ }^{19} \mathrm{~F}$ NMR (376.4 MHz, $\left.\mathrm{CDCl}_{3}\right): \delta-138.36--142.47(\mathrm{~m}, 2 \mathrm{~F}),-148.55-$ $-148.67(\mathrm{~m}, 1 \mathrm{~F}),-160.35--160.50(\mathrm{~m}, 2 \mathrm{~F}) .{ }^{13} \mathrm{C}$ NMR $(125.7 \mathrm{MHz}$, $\left.\mathrm{CDCl}_{3}\right): \delta 159.0,146.5-142.0(\mathrm{~m}, 2 \mathrm{C}), 138.8-136.5,108.2(\mathrm{dt}, J=$ $15.9 \mathrm{~Hz}$ and $J=3.9 \mathrm{~Hz}, 1 \mathrm{C}), 66.4,27.9,22.2$.

Pentane-1,5-diyl bis(4-azido-2,3,5,6-tetrafluorobenzoate) (13). Bis-ester $12(3.0 \mathrm{~g}, 6.1 \mathrm{mmol})$ and sodium azide $(0.84 \mathrm{~g}, 13.0 \mathrm{mmol})$ were dissolved in $14 \mathrm{~mL}$ of a 1:1 acetone:water solution and the mixture was heated to $80{ }^{\circ} \mathrm{C}$ for 4 hours. After cooling to room temperature, the reaction was quenched with water, diluted with diethyl ether and, as such, transferred in a separating funnel. The organic layer was washed with brine, dried over $\mathrm{MgSO}_{4}$, filtered and concentrated in vacuo. No further purification was found necessary: $3.3 \mathrm{~g}$ of bis-azide $13(6.1 \mathrm{mmol}, 100 \%)$ were obtained as a pale yellow solid. ${ }^{1} \mathrm{H}$ NMR $\left(500.1 \mathrm{MHz}, \mathrm{CDCl}_{3}\right): \delta 4.39$ (t, $\left.J=6.3 \mathrm{~Hz}, 2 \mathrm{H}\right), 1.79-1.84(\mathrm{~m}, 2 \mathrm{H})$, 
$1.61-1.56(\mathrm{~m}, 1 \mathrm{H}) .{ }^{19} \mathrm{~F}$ NMR $\left(470.5 \mathrm{MHz}, \mathrm{CDCl}_{3}\right): \delta-138.82-$ $-138.89(\mathrm{~m}, 2 \mathrm{~F}),-150.97--151.05(\mathrm{~m}, 2 \mathrm{~F}) .{ }^{13} \mathrm{C}$ NMR $(125.7 \mathrm{MHz}$, $\left.\mathrm{CDCl}_{3}\right): \delta 159.5,146.5-144.3(\mathrm{~m}, 1 \mathrm{C}), 141.6-139.5,123.4(\mathrm{tt}, J=$ $11.9 \mathrm{~Hz}$ and $J=3.0 \mathrm{~Hz}, 1 \mathrm{C}$ ), 107.9 (t, $J=15.5 \mathrm{~Hz}, 1 \mathrm{C}$ ), 66.4, 28.1, 22.4. HRMS (ESI-TOF) $\mathrm{m} / z$ : $[\mathrm{M}+\mathrm{Na}]^{+}$calcd. for $\mathrm{C}_{19} \mathrm{H}_{10} \mathrm{~F}_{8} \mathrm{~N}_{6} \mathrm{NaO}_{4}$, 561.0516; found 561.0528.

5-((4-(4-(4-(diphenylphosphoryl)phenyl)-5-iodo-1H-1,2,3-triazol1-yl)-2,3,5,6-tetrafluoro benzoyl)oxy) pentyl 4-(4-(4-(diphenyl phosphoryl)phenyl)-5-iodo-1H-1,2,3-triazol-1-yl)-2,3,5,6-

tetrafluorobenzoate (11). Ligand TBTA $(47.7 \mathrm{mg}, 0.09 \mathrm{mmol})$ was stirred in dry THF $(3.8 \mathrm{~mL})$ with copper iodide $(17.1 \mathrm{mg}, 0.09 \mathrm{mmol})$ for 20 minutes. Iodoalkyne $4(0.79 \mathrm{~g}, 1.80 \mathrm{mmol})$ and bis-azide $\mathbf{1 3}$ $(0.50 \mathrm{~g}, 0.93 \mathrm{mmol})$ were dissolved in THF $(5.0 \mathrm{~mL})$ and added in a single portion to the catalyst mixture. After stirring at room temperature overnight, the reaction mixture was quenched with an aqueous ammonium hydroxide solution $(10 \%, 1.8 \mathrm{~mL})$ and concentrated under reduced pressure. The crude mixture was then redissolved in ethylacetate and washed with water, brine and dried over $\mathrm{MgSO}_{4}$ filtered and concentrated in vacuo. Purification was achieved by crystallization from hot acetonitrile, affording product $\mathbf{1 1}$ as a white powder (0.89 g, $0.64 \mathrm{mmol}, 64 \%) .{ }^{1} \mathrm{H}$ NMR $\left(500.1 \mathrm{MHz}, \mathrm{CDCl}_{3}\right): \delta 8.19-$ $8.17(\mathrm{~m}, 4 \mathrm{H}), 7.84-7.80(\mathrm{~m}, 4 \mathrm{H}), 7.72-7.68(\mathrm{~m}, 8 \mathrm{H}), 7.59-7.55(\mathrm{~m}$, $4 \mathrm{H}), 7.51-7.47(\mathrm{~m}, 8 \mathrm{H}), 4.51(\mathrm{t}, J=6.6 \mathrm{~Hz}, 4 \mathrm{H}), 1.94-1.88(\mathrm{~m}, 4 \mathrm{H})$, $1.69-1.65(\mathrm{~m}, 2 \mathrm{H}) .{ }^{19} \mathrm{~F}$ NMR $\left(470.5 \mathrm{MHz}, \mathrm{CDCl}_{3}\right): \delta-136.87-$ $-136.94(\mathrm{~m}, 2 \mathrm{~F}),-141.31--141.38(\mathrm{~m}, 2 \mathrm{~F}) .{ }^{31} \mathrm{P}$ NMR $(202.4 \mathrm{MHz}$, $\left.20 \mathrm{mM}, \mathrm{CDCl}_{3}\right): \delta 28.96 .{ }^{13} \mathrm{C}$ NMR $\left(125.7 \mathrm{MHz}, \mathrm{CDCl}_{3}\right): \delta 158.6$, $149.4,145.9-143.6(\mathrm{~m}, 1 \mathrm{C}), 144.2-141.9(\mathrm{~m}, 1 \mathrm{C}), 133.5(\mathrm{~d}, J=$ 103.4 Hz, 1C), 132.7 (d, $J=10.8 \mathrm{~Hz}, 1 \mathrm{C}), 132.3$ (d, $J=2.8 \mathrm{~Hz}, 1 \mathrm{C}$ ), 132.2 (d, $J=9.9 \mathrm{~Hz}, 1 \mathrm{C}), 131.8,128.7$ (d, $J=11.9 \mathrm{~Hz}, 1 \mathrm{C}), 127.3(\mathrm{~d}, J$ $=12.0 \mathrm{~Hz}, 1 \mathrm{C}), 118.6-118.4(\mathrm{~m}, 1 \mathrm{C}), 116.1(\mathrm{t}, J=16.6 \mathrm{~Hz}, 1 \mathrm{C}), 80.9$, 67.2, 28.1, 22.4. HRMS (ESI-TOF) $m / z:[\mathrm{M}+\mathrm{H}]^{+}$calcd. for $\mathrm{C}_{59} \mathrm{H}_{39} \mathrm{~F}_{8} \mathrm{I}_{2} \mathrm{~N}_{6} \mathrm{O}_{6} \mathrm{P}_{2}, 1395.0368$; found 1395.0328. M.p. $>197.2{ }^{\circ} \mathrm{C}$ dec.

\section{ASSOCIATED CONTENT}

\section{Supporting Information}

X-ray data, NMR titration data, ${ }^{1} \mathrm{H}$ DOSY NMR data, energies from DFT calculations and coordinates of calculated structures, NMR spectra. This material is available free of charge the Internet at http://pubs.acs.org.

Crystallographic data have been deposited with the Cambridge Crystallographic Data Centre as supplementary publication CCDC-1514930 (2), CCDC-1514931 (4), CCDC-1514932 (6). Copies of the data can be obtained free of charge upon application to the CCDC.

\section{AUTHOR INFORMATION}

\section{Corresponding Author}

* E-mail: d.philp@st-andrews.ac.uk.

\section{ACKNOWLEDGMENT}

We thank the Marie Curie Initial Training Network on Replication and Adaption in Networks (ReAd) for financial support (early stage researcher funding to L. M.). We thank Mrs Melanja Smith and Dr. Filippo Stella for assistance with NMR experiments and Mr Lars Thode for measuring the association constant for the complex [PFIB-TPPO] in $d_{8}$-toluene.

\section{REFERENCES}

(1) (a) Metrangolo, P.; Neukirch, H.; Pilati, T.; Resnati, G. Acc. Chem. Res. 2005, 38, 386-395. (b) Desiraju, G. R.; Ho, P. S.; Kloo, L.; Legon, A. C.; Marquardt, R.; Metrangolo, P.; Politzer, P.; Resnati, G.; Rissanen, K. Pure Appl. Chem. 2013, 85, 1711-1713. (c) Gilday, L. C.; Robinson, S. W.; Barendt, T. A.; Langton, M. J.; Mullaney, B. R.; Beer, P. D. Chem. Rev. 2015, 115, 7118-7195. (c) Cavallo, G.;
Metrangolo, P.; Milani, R.; Pilati, T.; Priimagi, A.; Resnati, G.; Terraneo, G. Chem. Rev. 2016, 116, 2478-2601.

(2) (a) Lunghi, A.; Cardillo, P.; Messina, M. T.; Metrangolo, P.; Panzeri, W.; Resnati, G. J. Fluor. Chem. 1998, 91, 191-194. (b) Farina, A.; Meille, S.; Messina M. T.; Metrangolo, P.; Politzer, P.; Vecchio, G. Angew. Chem. Int. Ed. 1999, 38, 2433-2436. (c) Metrangolo, P.; Resnati, G. P. Chem. -Eur. J. 2001, 7, 2511-2519. (d) Fox, D. B.; Liantonio, R.; Metrangolo, P.; Pilati, T.; Resnati, G. J. Fluor. Chem. 2004, 125, 271-281.

(3) (a) Brinck, T.; Murray, J. S; Politzer, P. Int. J. Quantum Chem. 1992, 44, 57-64. (b) Pedireddi, V. R.; Reddy, D. S.; Goud, B. S.; Craig, D. C.; Rae, D. A; Desiraju, G. R. J. Chem. Soc., Perkin. Trans. 2 1994, 2353-2360. (c) Legon, A. C. Angew. Chem. Int. Ed. 1999, 38 , 2686-2714. (d) Pascal, A.; Hays, F. A.; Westhof, E.; Ho, P. S. Proc. Natl. Acad. Sci. USA 2004, 101, 16789-16794.

(4) (a) Metrangolo, P.; Meyer, F.; Pilati, T.; Resnati, G.; Terraneo, G. Angew. Chem. Int. Ed. 2008, 47, 6144-6127. (b) Mukherjee, A.; Tothadi, S.; Desiraju, G. R. Acc. Chem. Res. 2014, 47, 2514-2524. (c) Catalano, L.; Pérez-Estrada, S.; Terraneo, G.; Pilati, T.; Resnati, G.; Metrangolo, P.; Garcia-Garibay, M. A. J. Am. Chem. Soc. 2015, 137, 15386-15389. (d) Topić, F.; Rissanen, K. J. Am. Chem. Soc. 2016, $138,6610-6616$.

(5) (a) Parisini, E.; Metrangolo, P.; Pilati, T.; Resnati, G.; Terraneo, G. Chem. Soc. Rev. 2011, 40, 2267-2278. (b) Lange, A.; Guenther, M.; Buettner, F. M.; Zimmermann, M. O.; Heidrich, J.; Hennig, S.; Zahn, S.; Schall, C.; Sievers-Englers, A.; Ansideri, F.; Koch, P.; Laemmerhofer, M.; Stehle, T.; Laufer, S. A.; Boeckler, F. M. J. Am. Chem. Soc. 2015, 137, 14640-14652. (c) Persch, E.; Dumele, O.; Diederich, F. Angew. Chem. Int. Ed. 2015, 54, 3290-3327. (d) Coates Ford M.; Ho, P. S. J. Med. Chem. 2016, 59, 1655-1670.

(6) (a) Sun, A.; Lauher, J. W.; Goroff, N. S. Science 2006, 312, 1030-1034. (b) Priimagi, A.; Cavallo, G.; Metrangolo, P.; Resnati, G. Acc. Chem. Res. 2013, 46, 2686-2695. (c) Meyer, F.; Dubois, P. CrystEngComm 2013, 15, 3058-3071. (d) Bertolani, A.; Pirrie, L.; Stefan, L.; Houbenov, N.; Haataja, J. S.; Catalano, L.; Terraneo, G.; Giancane, G.; Valli, L.; Milani, R.; Ikkala, O.; Resnati, G.; Metrangolo, P. Nat. Commun. 2015, 6, 7574.

(7) (a) Shirman, T.; Arad, T.; van der Boom, M. E. Angew. Chem. Int. Ed. 2010, 49, 926-929. (b) Shirman, T.; Kaminker, R.; Freeman, D.; ACS Nano 2011, 5, 6553-6563. (c) Boterashvili, M.; Lahav, M.; Shankar, S.; Facchetti, A.; van der Boom, M. E. J. Am. Chem. Soc. 2014, 136, 11926-11929.

(8) (a) Rege, P. K.; Malkina, O. L.; Goroff, N. S. J. Am. Chem. Soc. 2002, 124, 370-371. (b) Sarwar, M. G.; Dragisic, L.; Salsberg, C.; Gouliaras, C.; Taylor, M. S. J. Am. Chem. Soc. 2010, 130, 16461653. (c) Chudzinsky, M. G.; Taylor, M. S. J. Org. Chem. 2012, 77, 3483-3491. (d) Dumele, O.; Wu, D.; Trapp, N.; Goroff, N. S.; Diederich, F. Org. Lett. 2014, 16, 4722-4725.

(9) (a) Zapata, F.; Caballero, A.; White, N. G.; Claridge, T. D. W.; Costa, P. J.; Felix, V.; Beer, P. D. J. Am. Chem. Soc. 2012, 134, 11533-11541. (b) Caballero, A.; Zapata, F.; White, N. G.; Costa, P. J.; Felix, V.; Beer, P. D. Angew. Chem. Int. Ed. 2012, 51, 1876-1880. (c) Mullaney, B. R.; Thompson, A. L.; Beer, P. D. Angew. Chem. Int. Ed. 2014, 53, 11458-11462. (d) Langton, M. G.; Robinson, S. W.; Marques, V.; Felix, V.; Beer, P. D. Nat. Chem. 2014, 6, 1039-1043. (e) Lim, J. Y. C.; Beer, P. D. Chem. Commun. 2015, 51, 3686-3688. (f) Barendt, T. A.; Robinson, S. W.; Beer, P. D. Chem. Sci. 2016, 7, 5171-5180. (g) Barendt, T. A.; Docker, A.; Marques, I.; Felix, V.; Beer, P. D. Chem. Sci. 2016, 55, 11069-11076. (h) Robinson, S. W.; Beer, P. D. Org. Biomol. Chem. 2017, 15, 153-159.

(10) (a) Walter, S. M.; Kniep, F.; Herdtweck, E.; Huber, S. M. Angew. Chem. Int. Ed. 2011, 50, 7187-7191. (b) Walter, S. M.; Jungbauer, S. H.; Kniep, F.; Schindler, S.; Herdtweck, E.; Huber, S. M. J. Fluor. Chem. 2013, 150, 14-20. (c) He, W.; Ge, Y. C.; Tan, C. H. Org. Lett. 2014, 16, 3244-3247. (d) Takeda, Y.; Hisakuni, D.; Lin, C. H.; Minakata, S. Org. Lett. 2015, 17, 318-321. (e) Jungbauer, S. H.; Huber, S. M. J. Am. Chem. Soc. 2015, 137, 12110-12120.

(11) (a) Hunter, C. A.; H. L. Anderson Angew. Chem. Int. Ed. 2009, 48, 7488-7499. (b) Ercolani, G.; Schiaffino, L. Angew. Chem. Int. Ed. 2011, 50, 1762-1768. 
(12) Jungbauer, S. H.; Bulfield, D.; Kniep, F.; Lehmann, C. W.; Herdtweck, E.; Huber, S. M. J. Am. Chem. Soc. 2014, 136, 1674016743.

(13) (a) Dumele, O.; Trapp, N.; Diederich, F. Angew. Chem. Int. Ed. 2015, 54, 12339-12344. (b) Dumele, O.; Schreib, B.; Warzok, U.; Trapp, N.; Schalley, C. A.; Diederich, F. Angew. Chem. Int. Ed. 2015, $56,1152-1157$.

(14) Vanderkooy, A.; Taylor, M. S. J. Am. Chem. Soc. 2015, 137, $5080-5086$

(15) (a) Zhao, X.; Chang, Y. -L.; Fowler, F.; Lauher, J. W. J. Am. Chem. Soc. 1990, 112, 6627-6634. (b) Etter, M. C.; Reutzel, S. M. J Am. Chem. Soc. 1991, 113, 2586-2598. (c) Harris, K. D. M.; Kariuki, B. M.; Lambropoulos, C.; Philp, D.; Robinson, J. M. A. Tetrahedron 1997, 53, 8599-8612.

(16) (a) Kyogoku, Y.; Lord, R. C.; Rich, A. Proc. Natl. Acad. Sci. USA 1967, 57, 250-257. (b) Jorgenson, W. L.; Pranata, J. J. Am Chem. Soc. 1990, 112, 2008-2010. (c) Park, T. K.; Schroeder, J.; Rebek, J. Jr. J. Am. Chem. Soc. 1991, 113, 5125-5127.

(17) (a) Gallant, M.; Viet, M. T. P.; Wuest, J. D. J. Am. Chem. Soc. 1991, 113, 721-723. (b) Sessler, J. L.; Wang, R. J. Am. Chem. Soc. 1996, 118, 9808-9809. (c) Beijer, F. H.; Kooijman, H.; Spek, A. L.; Sijbesma, R. P.; Meijer, E. W. Angew. Chem. Int. Ed. 1998, 37, 7578

(18) Maugeri, L.; Asencio-Hernández, J.; Lébl, T; Cordes, D. B.; Slawin, A. M. Z.; Delsuc, M. -A.; Philp, D Chem. Sci. 2016, 7, 64226428.

(19) Maugeri, L.; Jamieson E. M. G.; Cordes, D. B.; Slawin A. M. Z.; Philp, D. Chem. Sci. 2016 DOI: 10.1039/C6SC03696A.

(20) Putreddy, R.; Jurček, O.; Bhowik, S.; Mäkelä, T.; Rissanen, K. Chem. Commun. 2016, 52, 2338-2341.

(21) Papers describing $N$-oxides as XB acceptor: (a) Messina, M. T.; Metrangolo, P.; Panzeri, W.; Pilati, T.; Resnati, G. Tetrahedron 2001, 57, 8543-8550. (b) Aakeroy, C. B.; Wijethunga, T. K.; Desper, J. CrystEngComm 2014, 16, 28-31. (c) Aakeroy, C. B.; Wijethunga, T. K.; Benton, J.; Desper, J. Chem. Commun. 2015, 51, 2425-2428.

(22) (a) Gao, K.; Goroff, N. S. J. Am. Chem. Soc. 2000, 122, 9320-9321. (b) Cinčič, D.; Friščić, T.; Jones, W. CrystEngComm 2011, 13, 3224-3231. (c) Oh, S. Y.; Nickles, C. W.; Garcia, F.; Jones, W.; Friščić, T. CrystEngComm 2012, 14, 6110-6114. (d) Xu, Y.; Viger-Gravel, J.; Korobkov, I.; Bryce, D. L. J. Phys. Chem. C 2015, $119,27104-27117$

(23) Cabot, R.; Hunter, C. A. Chem. Commun. 2009, 2005-2007.

(24) (a) Johson, E. R.; Keinan, S.; Mori-Sànchez, P.; ContrerasGarcía, J.; Cohen, A. J.; Yang, W. J. J. Am. Chem. Soc. 2010, 132, 6498-6506. (b) Contreras-García, J.; Chaudret, R.; Piquemal, J. -P.; Yang, W. J. J. Chem. Theory Comput. 2011, 7, 625-632.

(25) (a) Glendening, E. D.; Landis, C. R.; Weinhold, E. J. J. Comput. Chem. 2013, 34, 1429-1437. (b) NBO 6.0. Glendening, E. D.; Badenhoop, J. K.; Reed, A. E.; Carpenter, J. E.; Bohmann, J. A.; Morales, C. M.; Landis, C. R.; Weinhold, E. J. Theoretical Chemistry Institute, University of Wisconsin, Madison, 2013.

(26) Hynes, M. J. J. Chem. Soc. Dalt. Trans. 1993, 311-312.

(27) (a) Bell, A. D.; Díaz, S. G.; Lynch, V. M.; Anslyn, E. V. Tetrahedron Lett. 1995, 36, 4155-4158. (b) Bisson, A. P.; Hunter, C. A. Chem. Commun. 1996, 1723-1724. (c) Camara-Campos, A.; Musumeci, D.; Hunter, C. A.; Turega, S. J. Am. Chem. Soc. 2009, 131, $18518-18524$.

(28) Hein, J. E.; Tripp, J. C.; Krasnova, L. B.; Sharpless, K. B.; Fokin, V. V. Angew. Chem. Int. Ed. 2009, 48, 8018-8021.

(29) Keana, J. F. W.; Cai, S. X. J. Org. Chem. 1990, 55, 36403647.
(30) Jencks, W. P. Proc. Natl. Acad Sci. USA 1981, 78, 40464050 .

(31) (a) Kassianidis, E.; Philp, D. Angew. Chem. Int. Ed. 2006, 45, 6344-6348. (b) Del Amo, V.; Slawin, A. M. Z.; Philp, D. Org. Lett. 2008, 10, 4589-4592. (c) Nowosinski, K.; von Krbek, L. K. S.; Traulsen, N. L., Schalley, C. A. Org. Lett. 2015, 17, 5076-5079.

(32) (a) Brunsveld, L.; Folmer, B. J. B.; Meijer, E. W.; Sijbesma, R. P. Chem. Rev. 2001, 101, 4071-4098. (b) De Greef, T. F. A.; Smulders, M. M. J.; Wolffs, M.; Schenning, A. P. H. J. Chem. Rev. 2009, 109, 5687-5754. (c) Yang, L.; Tan, X.; Wang, Z.; Zhang, X. Chem. Rev. 2015, 115, 7196-7239.

(33) De Greef, T. F. A.; Smulders, M. M. J.; Wolffs, M.; Schenning A. P. H. J.; Sijbesma R. P.; Meijer, E. W. Chem. Rev. 2009, 109, $5687-5754$.

(34) (a) Chen, Z.; Lohr, A.; Saha-Möller, C. R.; Würthner, F. Chem. Soc. Rev. 2009, 38, 564-584. (b) Smulders, M. M. J.; Nieuwenhuizen, M. M. L.; de Greef, T. F. A.; van der Schoot, P.; Schen$\operatorname{ning}$ A. P. H. J.; Meijer, E. W. Chem. Eur. J. 2010, 16, 362-367. (c) Pannuswany, N.; Pantoş, G. D.; Smulders, M. M. J.; Sanders, J. K. M. J. Am. Chem. Soc. 2012, 134, 566-573.

(35) Ha-Thi, M. -H.; Souchon, V.; Hamdi, A.; Métivier, R.; Alain, V.; Nakatani, K.; Lacroix, P. G.; Genêt, J. -P.; Michelet, V.; Leray, I. Chem. Eur. J. 2006, 12, 9056-9065.

(36) Chan, T. R.; Hilgraf, R.; Sharpless, K. B.; Fokin, V. V. Org. Lett. 2004, 6, 2853-2855.

(37) Kanakarajan, K.; Haider, K.; Czarnik, A. W. Synthesis 1988, $566-568$.

(38) Frisch, M. J.; Trucks, G. W.; Schlegel, H. B.; Scuseria, G. E.; Robb, M. A.; Cheeseman, J. R.; Scalmani, G.; Barone, V.; Mennucci, B.; Petersson, G. A.; Nakatsuji, H.; Caricato, M.; Li, X.; Hratchian, H. P.; Izmaylov, A. F.; Bloino, J.; Zheng, G.; Sonnenberg, J. L.; Hada, M.; Ehara, M.; Toyota, K.; Fukuda, R.; Hasegawa, J.; Ishida, M.; Nakajima, T.; Honda, Y.; Kitao, O.; Nakai, H.; Vreven, T.; Montgomery, J. A., Jr., Peralta, J. E.; Ogliaro, F.; Bearpark, M.; Heyd, J. J.; Brothers, E.; Kudin, K. N.; Staroverov, V. N.; Kobayashi, R.; Normand, J.; Raghavachari, K.; Rendell, A.; Burant, J. C.; Iyengar, S. S.; Tomasi, J.; Cossi, M.; Rega, N.; Millam, J. M.; Klene, M.; Knox, J. E.; Cross, J. B.; Bakken, V.; Adamo, C.; Jaramillo, J.; Gomperts, R.; Stratmann, R. E.; Yazyev, O.; Austin, A. J.; Cammi, R.; Pomelli, C.; Ochterski, J. W.; Martin, R. L.; Morokuma, K.; Zakrzewski, V. G.; Voth, G. A.; Salvador, P.; Dannenberg, J. J.; Dapprich, S.; Daniels, A. D.; Farkas, O.; Foresman, J. B.; Ortiz, J. V.; Cioslowski, J.; Fox, D. J. Gaussian 09; Gaussian, Inc.: Wallingford, CT, 2009.

(39) Tao, J.; Perdew, J. P.; Staroverov, V. N.; Scuseria, G. E. Phys. Rev. Lett. 2003, 91, 146401.

(40) Weigend, F. ; Ahlrichs, R. Phys. Chem. Chem. Phys. 2005, 7, $3297-3305$

(41) (a) Feller, D. J. Comput. Chem., 1996, 17, 1571-1586. (b) Schuchardt, K. L.; Didier, B. T.; Elsethagen, T.; Sun, L.; Gurumoorthi, V.; Chase, J.; Li, J.; Windus, T. L. J. Chem. Inf. Model. 2007, 47, 1045-1052.

(42) K. A. Peterson J. Chem. Phys. 2003, 119, 11113.

(43) Ochterski, J. W. Thermochemistry in Gaussian; Gaussian Inc.: Wallingford, CT, 2000.

(44) Boys, S. F.; Bernardi, F. Mol. Phys. 1970, 19, 553-566.

(45) Humphrey, W.; Dalke, A.; Schulten, K. J. Mol. Graphics 1996, 14, 33-38. http://www.ks.uiuc.edu/Research/vmd/

(46) Kishikawa, K.; Haga, Y.; Inoue, T.; Watanabe, T.; Takahashi, M.; Kohmoto, S. Chem. Lett. 2012, 41, 1465-1467. 